\title{
Long-Term Rainfall Trends and Future Projections over Xijiang River Basin, China
}

\author{
Muhammad Touseef $\mathbb{D}^{1,2}$ Lihua Chen $\mathbb{D}^{1,},{ }^{1,2}$ Kaipeng Yang $\mathbb{D}^{1,2}$ and Yunyao Chen ${ }^{1,2}$ \\ ${ }^{1}$ College of Civil Engineering and Architecture, Guangxi University, Nanning 530004, China \\ ${ }^{2}$ Guangxi Key Laboratory of Disaster Prevention and Engineering Safety, Nanning 530004, China
}

Correspondence should be addressed to Lihua Chen; xdslclh@gxu.edu.cn

Received 9 October 2019; Revised 31 January 2020; Accepted 11 February 2020; Published 12 March 2020

Academic Editor: Francesco Viola

Copyright (c) 2020 Muhammad Touseef et al. This is an open access article distributed under the Creative Commons Attribution License, which permits unrestricted use, distribution, and reproduction in any medium, provided the original work is properly cited.

\begin{abstract}
Precipitation trend detection is vital for water resources development and decision support systems. This study predicts the climate change impacts on long-term precipitation trends. It deals with the analysis of observed historical (1960-2010) and arithmetic mean method in assembling precipitation from CMIP5 Global Climate Models (GCMs) datasets for a future period (2020-2099) under four emission scenarios. Daily precipitation data of 32 weather stations in the Xijiang River Basin were provided by National Meteorological Information Centre (NMIC) of the China Meteorological Administration (CMA) and Global Climate Models (GCMs) with all four emission scenarios statistically downscaled using Bias Correction Special Disaggregation (BCSD) and applied for bias correction via Climate Change Toolkit (CCT). Nonparametric Mann-Kendall test was applied for statistical significance trend analysis while the magnitude of the trends was determined by nonparametric Sen's estimator method on a monthly scale to detect monotonic trends in annual and seasonal precipitation time series. The results showed a declined trend was observed for the past 50 years over the basin with negative values of MK test (Z) and Sen's slope Q. Historical GCMs precipitation detected decreasing trends except for NoerESM1-M which observed slightly increasing trends. The results are further validated by historical precipitation recorded by the Climate Research Unit (CRU-TS-3.1). The future scenarios will likely be positive trends for annual rainfall. Significant positive trends were observed in monsoon and winter seasons while premonsoon and postmonsoon seasons will likely be slightly downward trends. The 2040 s will likely observe the lowest increase of $6.6 \%$ while the $2050 \mathrm{~s}$ will observe the highest increase of $11.5 \%$ over the $21^{\text {st }}$ century under future scenarios. However, due to the uncertainties in CMIP5, the future precipitation projections should be interpreted with caution. Thus, it could be concluded that the trend of change in precipitation around the Xijiang River Basin is on the increase under future scenarios. The results can be valuable to water resources and agriculture management policies, as well as the approach for managing floods and droughts under the perspective of global climate change.
\end{abstract}

\section{Introduction}

Quantifying rainfall on spatial and temporal scales has been of great interest for experts during the past century because of the indication of the global positive trend, even though negative trends were was observed in large areas globally [1]. Climate change and urbanization are two interlinked, welldefined, and increasing environmental phenomena in the $21^{\text {st }}$ century. Economic development at the local scale as well as global scale has affected the water resources. Global warming is one of the major reasons for climate change.
These two terms (global warming and climate change) alter the average temperature of Earth's climate system and related effects. China is in line with global warming but with specific characteristics. The average annual temperature increased from the 1920s to the 1940s, decreasing trends were from the 1950s to 1980s, and till date from the 1980s, the current temperature is rising. The latest decade in China was recorded as the warmest period. These trends were obviously more in southern China than in western, eastern, and northern China [2]. Rapid changes in human activities significantly imbalance the hydrological cycle, which result 
in frequent occurrence of extreme events [3]. Risks of natural floods due to numerous environmental changes and human activities created huge concerns for climate change experts [4]. Frequent extreme precipitation events cause severe floods that lead to runoff [5].

Global climate changes altered precipitation patterns and global temperature increases which could have a significant impact on the local hydrological cycle [6]. This increase in temperature and changes in the hydrological cycle raised stormwater flows which are easily understood. Precipitation patterns over the urban areas are affected by changes in surface albedo and vegetation cover. All these factors increase runoff due to retardation of the infiltration and evapotranspiration process [7]. The statistical downscaling model (SDSM) and Statistical Analog Resampling Scheme (STARS) were used to downscale the GCM outputs for projecting the future climate scenarios and performed well in simulating temperature and precipitation [8].

China has very swift economic growth in the past few decades. Urbanization which leads to significant impacts on land-use changes was an 8.5 million hectare square meter in 2013. According to the National Bureau Statistics of China, the municipal population exceeds $50 \%$ in recent years and this will be over $80 \%$ in 2050 by Yan et al. [9]. The southcentral and southwestern provinces of mainland China received the most prominent donors of migrants from 1995 to $2000[10,11]$. Pearl River Delta has not been a region of rapid land conversion historically for hundreds of years but the government directives in early 1980s regarding economic growth which directly upgraded the living standards and urbanization rate of $300 \%$ in the delta have serious impacts on various climate observations $[12,13]$. Since the 1980s, rapid economic growth and policy change turned the Pearl River Delta (PRD) region as the fastest populated region [13]. Water-Energy-Food Nexus alters as a result of migration from urban to rural areas owing to changes in the radiation process. The anthropogenic aerosols, carbon emissions, and high-rise buildings affect the air quality, local weather, and climate [14]. The anthropogenic forcing mainly includes the emissions of greenhouse gases (GHGs) as well as land-use/land-cover changes [15]. Ren et al. [16] presented evidence for the rapid urbanization effect. $0.05^{\circ} \mathrm{C}$ per decade increase in temperature is recorded as a result of urbanization in mainland China.

China observed an increase of $1.1^{\circ} \mathrm{C}$ from 1908 to 2007 in average surface temperature $[2,17]$. Extreme weather events have great impacts on the ecosystem and society. Various studies were conducted throughout the world to analyze the nature of extreme events and concluded that future climate change will increase the intensity and frequency of such events [18].

Recently, changes in precipitation trends have attracted the researcher's attention. Southern China observed a $30-50 \%$ increase in precipitation in the winter season (December, January, and February) from 1900 to 1999 $[19,20]$. Standardized Precipitation Index (SPI) trends across the Pearl River Basin for the monsoon characterized by decreasing SPI shows that dry days govern major parts of the Pearl River Basin while winter (December-February) is characterized by increasing SPI trends [21]. Variations of the annual and seasonal rainfall are not significant at $>95 \%$ confidence level. However, substantial negative trends can be observed in the number of wet days [22].

Liu et al. [23] detected an increase of $+1.8^{\circ} \mathrm{C}$ in annual air temperature from 1961 to 2007 at Pearl River Basin. Fischer et al. [24] applied the Mann-Kendall test to daily mean temperature for 157 stations and found significant positive trends of annual mean temperature. The study also summarized that the whole basin observed positive trends in annual and monthly mean temperatures; however, the temperature increased less in summer than in winter. Zhang et al. [25] applied the SWAT model to GCMs' outputs in Urumqi River, and both temperature and precipitation show increase in near and far future.

The long-term average precipitation of the Pearl River Basin is nearly $1500 \mathrm{~mm}$. Average of $2 \mathrm{~mm}$ per decade is observed in the changing rate in annual average precipitation by evaluating 42 rainfall stations. 110 rainy days with 1.4 days per decade is the changing magnitude for long-term annual average precipitation while $13.5 \mathrm{~mm}$ /day is the longterm annual average rainfall intensity with $0.14 \mathrm{~mm} /$ day per decade changing magnitude [26].

Gemmer et al. [27] also concluded their findings for 192 stations (1961-2007) for annual, monthly, and daily sums in the Pearl River Basin that autumn precipitation observed declined trends and spring, summer, and winter rainfall have inclined trends. The same findings were supported by many other researchers in their studies [22]. The East-Asian monsoon plays a key role in local rainfall trends, summarized by [28], that strong winter monsoon with northerly winds is governed by declined trends in winter season over southern China.

Gao et al. [29] recommended that high-resolution models are better to examine future climate projections over China and East Asia. Chen et al. [30] evaluated historical precipitation variability over $21^{\text {st }}$ century CMIP5 archive estimates which are put into context based on the $20^{\text {th }}$ century biases and concluded that CMIP5 models can produce better spatial patterns over CMIP3. Feng et al. [31] studied future projections based on the global AGCM over China and concluded that annual precipitation is close to the station data. The regional mean precipitation will increase in northern regions greater than southern regions in China based on the projections of 11 climate models under representative concentration pathway (RCP) scenarios [32]. Similarly, the Pearl River Basin will likely be inclined trends in precipitation under RCP2.6 and RCP4.5 scenarios, whereas declined trends under RCP8.5 [33].

Guo et al. [34] summarized that climate plays a key role in changing basin hydrology streamflow in the Xijiang River Basin, China. The Xijiang River Basin has the main tributary of the Pearl River Basin, which lies in the subtropical region of South China. The Pearl River Basin is the third largest river basin of China with more than 100 million people residing. Since 1990, the Xijiang River Basin observed frequent flood disasters due to heavy storm events [35]. A slightly increasing trend was observed historically (1951-2010) during the dry season of the Xijiang River Basin 
[36]. All these studies reveal that there are no significant similarities in rainfall trends at the regional level. For the management and planning at the regional or local scale, it has been found that continental or global scale studies of climate variables are not very beneficial [37]. Therefore, local climatic parameter studies are useful for better management. The rainfall trend analysis is important to evaluate the impact of climate change; therefore, in this study, an attempt has been made to determine the rainfall trends over the Xijiang River Basin. The primary aim of the present study is to analyze the changes in annual and seasonal rainfall for the historical period of 1960-2010 and future rainfall trends for the period of 2020-2099 using GCMs. A number of researchers $[27,35,38]$ have assessed the rainfall trends in the basin, and they found that seasonal variability is closely similar. For this purpose, Mann-Kendall test [39] and Kendall [40] are most widely used nonparametric tests [41-43] in this study to analyze annual and seasonal rainfall trends in time series.

\section{Materials and Methods}

2.1. Study Area. The selected study area is the Xijiang River Basin (Figure 1), which is the largest river basin contributing to the Pearl River Basin and located in South China. The total drainage area of the Xijiang River Basin is $3.05 \times 105 \mathrm{~km}^{2}$.

The basin has a humid and tropical climate with plentiful precipitation and generally high air temperature. The mean air temperature is nearly $14^{\circ} \mathrm{C}-22^{\circ} \mathrm{C}$. The mean annual precipitation varies from $1,200 \mathrm{~mm}$ to $1,900 \mathrm{~mm}$, with a diverse increase from the west to east. Precipitation mainly occurs from April to October, which accounts for $72 \%-86 \%$ of the annual precipitation [38].

2.2. Data Availability. Daily precipitation data of 32 weather stations (Figure 2) in the Xijiang River Basin for the period of 1960-2010 were provided by the National Meteorological Information Centre (NMIC) of the China Meteorological Administration (CMA).

2.2.1. Global Climate Models (GCMs) Data. This study analyzes the Climate Datasets from five (05) Global Climate Models (GCMs) (GFDL-ESM2M, HadGEM2-ES, IPSLCM5A-LR, MIROC-ESM-CHEM, and NorESM1-M) from ISI-MIP (Intersectoral Impact Model Intercomparison Project) [44], with all four scenarios (RCP-2.6, RCP-4.5, RCP-6.0, and RCP-8.5). The raw GCMs output is statistically downscaled (delta method) and Bias Correction Special Disaggregation (BCSD) is applied for bias correction using Climate Change Toolkit (CCT) [45-47]. This CCT package also includes historical climate data (1970-2006) from the Climate Research Unit (CRU-TS-3.1) which could be used as an observed dataset. All Climate Datasets are 0.5 degree spatial resolution downscaled and are available in a simple text format. Climate Change Toolkit (CCT) extracts, downscales, makes bias correction of, and interpolates the raw GCMs outputs. The package will analyze extreme events that are dry and wet days and analyze the past flooding trends in future data.

2.3. Trend Analysis. Long-term future and historical trend analysis and estimation of Sen's slope are evaluated using Kendall and Sen $[48,49]$ method, respectively, for given datasets. Parametric or nonparametric procedures are followed to detect a statistical trend which is a significant change over time, while trend analysis of a time series consists of the magnitude of the trend and its statistical significance [50]. Nonparametric Mann-Kendall test was used for statistical significance trend analysis while the magnitude of the trends was determined by nonparametric Sen's estimator method.

2.3.1. Mann-Kendall Test. Mann-Kendall test is a nonparametric test for finding trends in time series. This test is widely used because the data do not need to confirm any distribution [51-53]. This test checks the null hypothesis of no trend versus the alternative hypothesis of the presence of monotonic increasing or decreasing trend of hydroclimatic time series data. This test is more suitable for those time series where the trend may be considered as monotonic (consistently increasing or decreasing). Each data value in the time series is compared with all subsequent values. The Mann-Kendall test is applicable in cases when the data values $x_{i}$ of a time series can be assumed to obey the model in

$$
x_{i}=f\left(t_{i}\right)+\varepsilon_{i},
$$

where $f(t)$ is a monotonic function of time and the residuals $\varepsilon_{i}$ can be supposed to be from the same distribution with zero means. The variance of the distribution is constant in time. This study considers the null hypothesis of no trend $H_{o}$; that is, the observations $x_{i}$ are randomly ordered in time, against the alternative hypothesis $H_{1}$, where there is an increasing or decreasing monotonic trend. The net result of all such increments and decrements gives the final value of $S$ :

$$
S=\sum_{i=1}^{n-1} \sum_{j=i+1}^{n} \operatorname{sgn}\left(x_{j}-x_{i}\right)
$$

where $x_{j}$ and $x_{i}$ are annual values, $n$ is the number of data points, and $\operatorname{sgn}\left(x_{j}-x_{i}\right)$ can be calculated using

$$
\operatorname{sgn}\left(x_{j}-x_{i}\right)= \begin{cases}1, & \text { if } x_{j}-x_{i}>0, \\ 0, & \text { if } x_{j}-x_{i}=0, \\ -1, & \text { if } x_{j}-x_{i}<0 .\end{cases}
$$

A positive or negative value of $S$ defines increasing or decreasing trends, respectively. If the number of data $n$ value is 10 or more, the $S$ statistics behave as normally distributed and the test is performed with a normal distribution [54]. The mean, variance, and standard normal distribution $(Z$ statistics) is computed using 


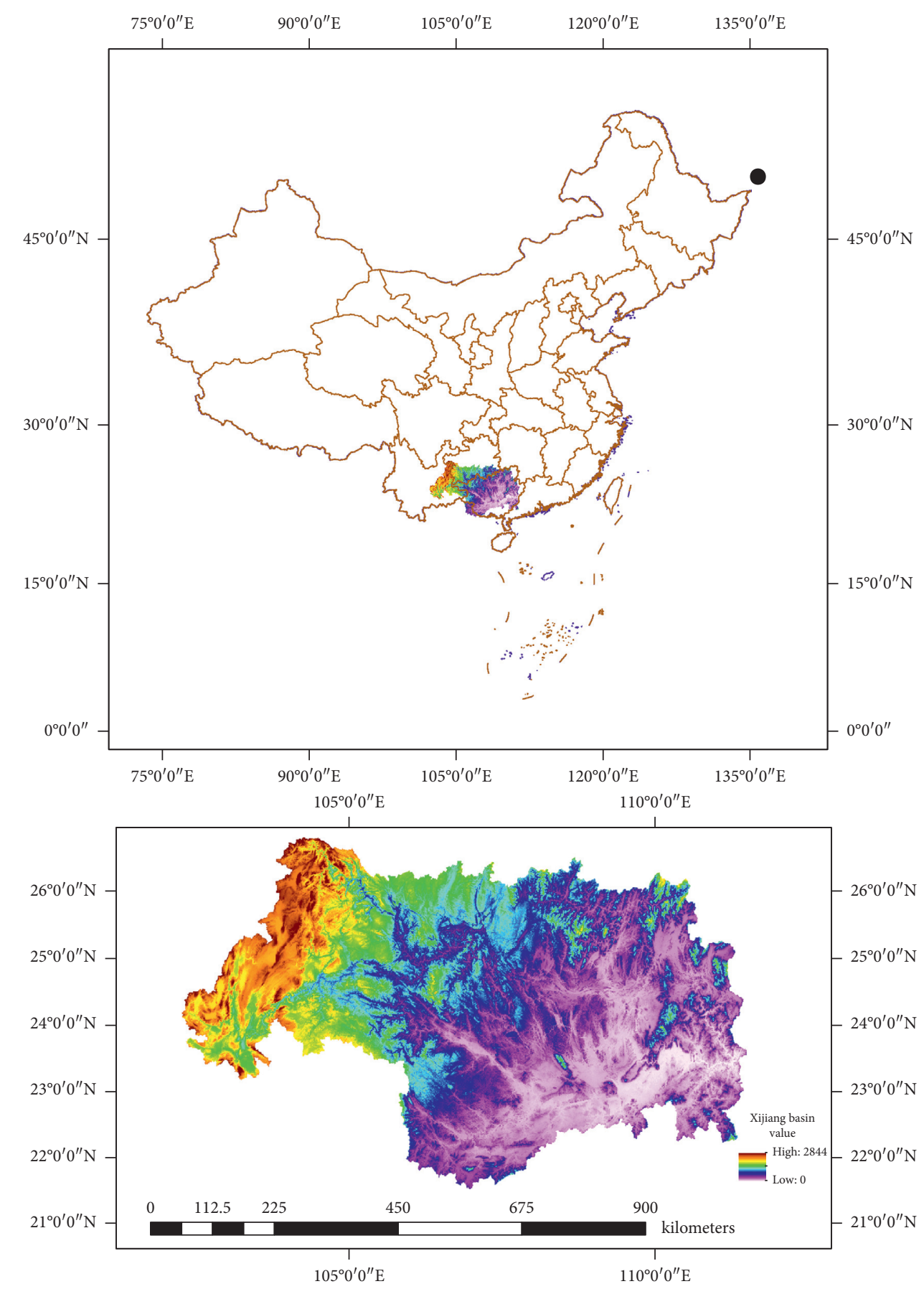

Figure 1: Location of the Xijiang River Basin.

$$
E(S)=0
$$

$\operatorname{Var}(S)=\frac{1}{18}\left[n(n-1)(2 n+5)-\sum_{i=1}^{n} t_{i}\left(t_{i}-1\right)\left(2 t_{i}+5\right)\right]$,

where $n$ is the number of data points and $t_{i}$ is the number of data points in the $i^{t h}$ group. The normal $Z$ statistics are computed using

$$
Z= \begin{cases}\frac{S-1}{\sqrt{\operatorname{VAR}(S)},} & \text { if } S>0, \\ 0, & \text { if } S=0, \\ \frac{S+1}{\sqrt{\operatorname{VAR}(S)},} & \text { if } S<0 .\end{cases}
$$

Negative $Z$ value indicates a decreasing trend and the computed $Z$ statistics is greater than the $Z$ value 


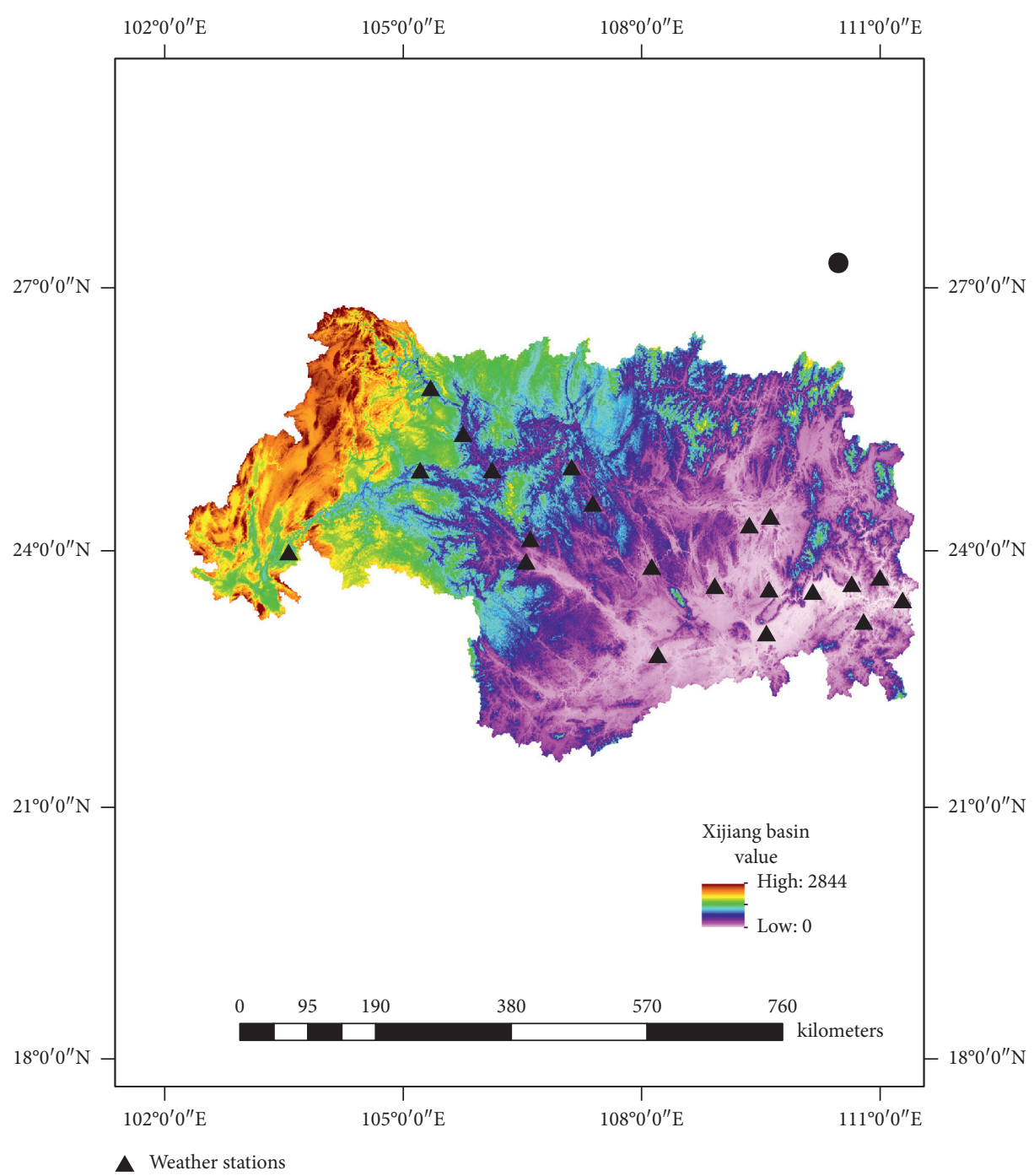

Figure 2: Location of weather stations.

corresponding to the $5 \%$ level of significance. A two-tailed test is used for significance level $\alpha: 0.1,0.05,0.01$, and 0.001 . 0.05 significance level means that there is a $5 \%$ probability that we make a mistake when rejecting null hypothesis $H_{0}$.

The Mann-Kendall test does not require that the data be normally distributed. It is not affected by missing data other than the fact that the number of sample points is reduced and hence might affect the statistical significance adversely. Mann-Kendall test output is not affected by the irregular spacing of the time points of measurement as well as the length of the time series. However, the Mann-Kendall test is not suited for data with periodicities. For this purpose, all periodic effects were removed by the prewhitening method from the data in the processing step before computing the Mann-Kendall test. Secondly, the Mann-Kendall test tends to give more negative results for shorter datasets; the longer the time series, the more effective the trend detection computation [41, 42].
2.3.2. Sen's Slope Method. Linear regression is one of the most widely used methods for detecting trends in time series. However, this method requires the assumption of normal distribution in residuals [55-57]. Many studies concluded that hydrological variables give right skewness due to the influence of natural phenomena and do not follow a normal distribution [58]. Sen's slope method is nonparametric and used for predicting the magnitude (true slope) and developing linear relationships [49]. Sen's slope is estimated as the median of all pairwise slopes between each pair of points in the dataset [59]. Each individual slope $m_{j k}$ is calculated using

$$
m_{j k}=\frac{y_{j}-y_{k}}{j-k},
$$

where $k=1,2,3, \ldots,(n-1)$ and $j=2,3, \ldots, n$, while $y_{j}$ and $y_{k}$ are data values at times $j$ and $k$. The median of the $n$ values of $m_{j k}$ is represented by Sen's slope of estimation given by 


$$
Q_{\mathrm{med}}= \begin{cases}m_{(n+1 / 2)}, & \text { for } n \text { is odd } \\ \frac{1}{2}\left(m_{(n / 2)}+m_{(n+2 / 2)}\right), & \text { for } n \text { is even }\end{cases}
$$

Positive Sen's estimator $Q_{\text {med }}$ indicates an increasing trend, while negative Sen's slope indicates a falling trend. $Q_{m e d}$ is computed using a $100(1-\alpha) \%$ confidence interval using a nonparametric test [54].

\section{Results}

3.1. Annual Rainfall Features. The initial analysis for this study included computing the mean, standard deviation (STD), coefficient of skewness $\left(\mathrm{C}_{s}\right)$, coefficient of kurtosis $\left(\mathrm{C}_{k}\right)$, and coefficient of variance $\left(\mathrm{C}_{y}\right)$ in the annual precipitation for every station for 51 years (1960-2010). Rainfall characteristics of the Xijiang River Basin are presented in Table 1. The mean annual precipitation varied between $851.3 \mathrm{~mm}$ at a higher altitude at the upper basin and $1883 \mathrm{~mm}$ precipitation at the north of the basin in the Guilin area. For normal distribution coefficient of skewness and coefficient of kurtosis values are 0 and 3, respectively. Table 1 indicates that for most of the station dataset is positively skewed and negative kurtosis represents light-tailed distribution. Coefficient of variation represents the extent of variability of data sample relative to the mean of the population. The coefficient of variation varied between $13.1 \%$ at Dushan station and $22.2 \%$ at Guangnan station. The average spatial variability of the precipitation over the Xijiang River Basin is $17 \%$.

\subsection{Historical Temporal Precipitation Trends on Seasonal and} Annual Scale. Long-term historical trends were assessed in this study for the period of 1960-2010. The Mann-Kendall (MK) test was applied on a monthly scale to detect trends in precipitation time series. Figure 3 presents the mean annual, monsoon JJA (June-August), Winter DJF (December-February), premonsoon MAM (March-May), and postmonsoon SON (September-November) precipitation. The mean annual precipitation is $1360 \mathrm{~mm}$ for the basin. The declined trend is observed for the past 50 years over the basin with MK test $Z$ value -0.71 and Sen's slope $Q$ value of -1.063 . Average rainfall in the monsoon season was $670 \mathrm{~mm}$ which was $49.3 \%$ contribution to the annual rainfall. A slightly increasing trend was recorded in average monsoon precipitation with MK test $Z$ value of 0.34 and Sen's slope Q value is 0.247 . Winter season is almost dry having an average rainfall of $95.27 \mathrm{~mm}$ precipitation over the basin. Winter season contributed with $7 \%$ rainfall to the annual mean precipitation with the significant increasing trend of MK test $Z$ value 1.92 and Sen's slope $Q$ value 0.631 . Premonsoon and postmonsoon observed decreasing trends with a mean precipitation of $358.63 \mathrm{~mm}$ and $235.37 \mathrm{~mm}$, respectively.

Premonsoon also got significant rainfall which contributed with $26.4 \%$ while postmonsoon contributed only with $17.32 \%$ to the annual mean rainfall over the basin. MK test $Z$ statistics for premonsoon and postmonsoon are -0.76 and -2.26 , respectively. Sen's slope $Q$ value is -0.430 and -1.344 , respectively. Postmonsoon (September-November) observed a significant decrease while the Winter season (December-February) observed substantial inclination (Figures 4(a)-4(e)).

3.3. Spatial Distribution of Historical Rainfall Trends. Elevation affects precipitation significantly, especially in hilly areas. Spatial variation in rainfall trends over the Xijiang Basin was significant in the past few decades. Low altitude areas received a significant amount of rainfall. Upper Xijiang Basin consisting of Nanpanjiang and Beipanjiang is at higher altitudes ( $>1500$ meters) which received less precipitation relative to lower altitudes, Guilin, Gaoyao, Duan, Wangmo, and other similar areas. The arid conditions of the higher altitudes in the basin are because of the leeward side of the mountain. Table 2 presents the MK test $Z$ statistics and Sen's slope $S$ statistics of stations.

The above table concluded that the average values of $Z$ and $Q$ statistics for annual rainfall are -0.394 and -0.776 , respectively. These values summarized that there was a declining trend over the Xijiang Basin. The trends were varying but 21 stations observed a decrease in precipitation. Longzhou station which is at low altitude has the lowest Sen's slope $Q$ magnitude while Mengshan station has the highest Sen's slope $Q$ magnitude value. Monsoon observed a slight increase with an average Sen's slope $Q$ magnitude of 0.177 over the basin. 16 stations have declined trend while the remaining showed positive trends. Guilin station has a significant increasing trend in monsoon season with Sen's slope $Q$ magnitude value of 4.550 , while Nanning has a slight decline trend with the lowest $Q$ magnitude of -0.032 in monsoon season. Winter season observed increasing trend with $Z$ statistics 1.33 and Sen's slope $Q$ magnitude of 0.78 . All stations observed increasing trends in the winter season. Premonsoon and postmonsoon seasons were influenced by declining trends. All stations observed decreasing trends over the Xijiang River Basin in postmonsoon while 18 stations showed negative trends in premonsoon.

Guilin station situated at the lower basin has an average mean precipitation of $1883.33 \mathrm{~mm}$. Annual rainfall has a slightly increasing trend in Figure 5(a), winter and monsoon seasons have a significant increase in Figures 5(b) and 5(c), while premonsoon and postmonsoon Figures 5(d) and 5(e) observed a decreasing trend in precipitation.

Figures 6(a)-6(e) represent the annual and seasonal mean precipitation trends of Zhanyi station which is situated in the upper basin. This station received less amount of precipitation in history. Annual precipitation was significantly decreased. Similar declination was followed by monsoon and postmonsoon mean precipitation. This area observed increasing trends in winter and premonsoon season.

3.4. Future Precipitation Trends. This study projected the future prediction of precipitation Climate Datasets using the arithmetic mean (AM) assemble of five (05) Global Climate Models (GCMs) (GFDL-ESM2M, HadGEM2-ES, IPSL- 
TABLE 1: Summary of geographic conditions and mean annual precipitation statistics for the study area.

\begin{tabular}{|c|c|c|c|c|c|c|c|c|c|}
\hline Station name & Station number & Longitude & Latitude & Elevation (m) & Mean $(\mathrm{mm})$ & STD & $\mathrm{C}_{s}$ & $\mathrm{C}_{k}$ & $\mathrm{C}_{v}$ \\
\hline Wei Ning & 56691 & 104.28 & 26.87 & 2237.5 & 879.1 & 161.2 & 0.5 & -0.6 & 18.3 \\
\hline Zhanyi & 56786 & 103.83 & 25.58 & 1898.7 & 867.1 & 167.1 & 0.6 & -0.7 & 17 \\
\hline Panxian & 56793 & 104.62 & 25.78 & 1515.2 & 1247.3 & 219.7 & 0.4 & 1.2 & 16 \\
\hline Yuxi & 56875 & 102.55 & 24.35 & 1636.7 & 902.9 & 151.7 & 0.3 & 1.4 & 16.8 \\
\hline Luxi & 56886 & 103.77 & 24.53 & 1704.3 & 917.8 & 153.1 & 0.5 & 0.3 & 16.7 \\
\hline Mengzi & 56985 & 103.38 & 23.38 & 1300.7 & 851.3 & 151.3 & -0.1 & -0.4 & 17.8 \\
\hline Anshun & 57806 & 105.92 & 26.25 & 1392.9 & 1329.5 & 221.0 & -0.3 & 0.2 & 16.6 \\
\hline Xingyi & 57902 & 105.18 & 25.43 & 1378.5 & 1224.2 & 218.6 & 0.1 & 0.5 & 16.4 \\
\hline Wangmo & 57906 & 106.08 & 25.18 & 566.8 & 1238.7 & 184.8 & 0.0 & 0.3 & 14.9 \\
\hline Luodian & 57916 & 106.77 & 25.43 & 440.3 & 1141.4 & 202.0 & 0.1 & -0.7 & 17.7 \\
\hline Dushan & 57922 & 107.55 & 25.83 & 1013.3 & 1311.7 & 171.5 & 0.0 & -0.2 & 13.1 \\
\hline Rongjiang & 57932 & 108.53 & 25.97 & 285.7 & 1436.2 & 198.6 & 0.1 & -0.7 & 16.7 \\
\hline Rongan & 57947 & 109.40 & 25.22 & 121.3 & 1785.9 & 279.8 & 0.2 & -0.3 & 14.8 \\
\hline Guilin & 57957 & 110.30 & 25.32 & 164.4 & 1883.3 & 326.5 & 0.1 & 0.7 & 17.3 \\
\hline Guangnan & 59007 & 105.07 & 24.07 & 1249.6 & 1053.7 & 233.9 & 0.3 & 11.7 & 22.2 \\
\hline Fengshan & 59021 & 107.03 & 24.55 & 484.6 & 1530.4 & 278.8 & 0.2 & -0.4 & 18.2 \\
\hline Hechi & 59023 & 108.05 & 24.70 & 211 & 1872.4 & 288.5 & 0.6 & 5.1 & 15.4 \\
\hline Duan & 59037 & 108.10 & 23.93 & 170.8 & 1725.1 & 289.2 & -0.1 & -0.4 & 16.8 \\
\hline Liuzhou & 59046 & 109.40 & 24.35 & 96.8 & 1445.1 & 307.8 & 0.1 & 0.0 & 21.3 \\
\hline Mengshan & 59058 & 110.52 & 24.20 & 145.7 & 1743.8 & 319.4 & 0.6 & -0.2 & 18.3 \\
\hline Hezhou & 59065 & 111.52 & 24.42 & 108.8 & 1552.6 & 306.7 & 0.6 & 0.1 & 19.8 \\
\hline Napo & 59209 & 105.83 & 23.42 & 793.6 & 1385.6 & 207.3 & -0.1 & -0.5 & 15.0 \\
\hline Baise & 59211 & 106.60 & 23.9 & 173.50 & 1322 & 222.9 & -0.1 & -0.6 & 20.3 \\
\hline Jingxi & 59218 & 106.42 & 23.13 & 739.4 & 1629.3 & 260.3 & -0.1 & -0.2 & 16.0 \\
\hline Laibin & 59242 & 109.23 & 23.75 & 84.90 & 1341.8 & 252.5 & 0.5 & -0.5 & 18.8 \\
\hline Guiping & 59254 & 110.08 & 23.40 & 42.50 & 1712.3 & 325.5 & 0.1 & 0.1 & 19.0 \\
\hline Wuzhou & 59265 & 111.3 & 23.48 & 114.8 & 1468.3 & 239.4 & 0.0 & -0.2 & 16.3 \\
\hline Gaoyao & 59278 & 112.47 & 23.05 & 7.1 & 1647.5 & 266.5 & 0.0 & -0.6 & 16.2 \\
\hline Longzhou & 59417 & 106.85 & 22.33 & 128.8 & 1282.2 & 224.1 & 0.0 & -0.7 & 17.5 \\
\hline Nanning & 59431 & 108.35 & 22.82 & 73.1 & 1413.1 & 236.0 & 0.4 & 0.5 & 18.1 \\
\hline Xinyi & 59456 & 110.93 & 22.35 & 84.6 & 1777.5 & 378.8 & 0.0 & -0.2 & 21.3 \\
\hline Louding & 59462 & 111.57 & 22.77 & 53.3 & 1540.6 & 252.5 & 0.5 & -0.5 & 18.8 \\
\hline
\end{tabular}

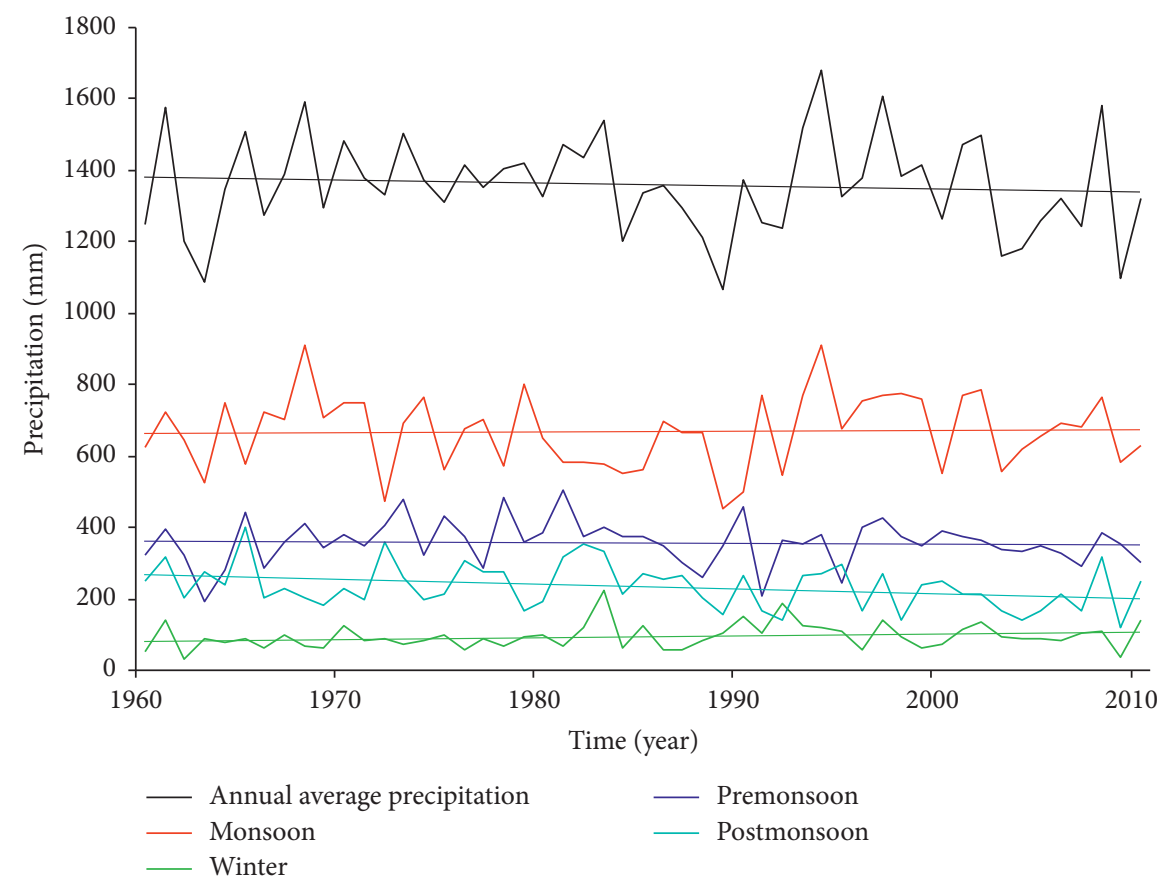

FIgURE 3: Annual and seasonal average precipitation trends over the Xijiang Basin (1960-2010). 


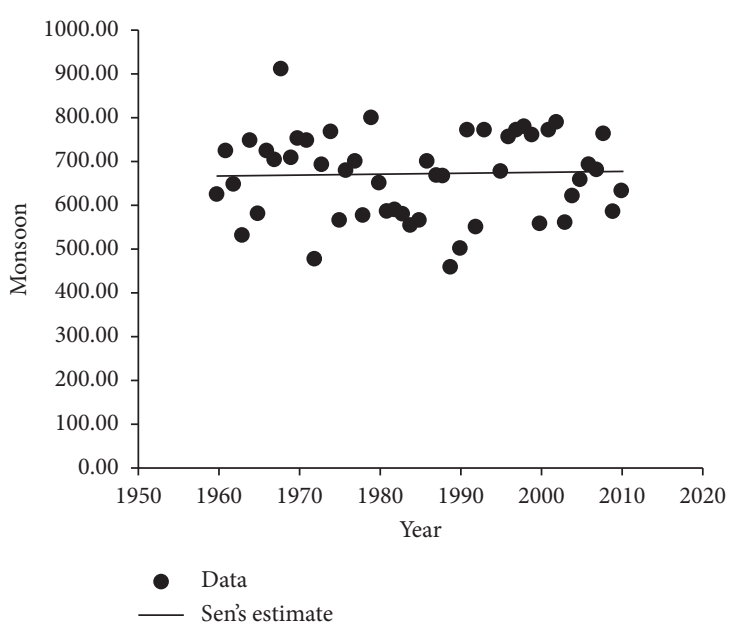

(a)

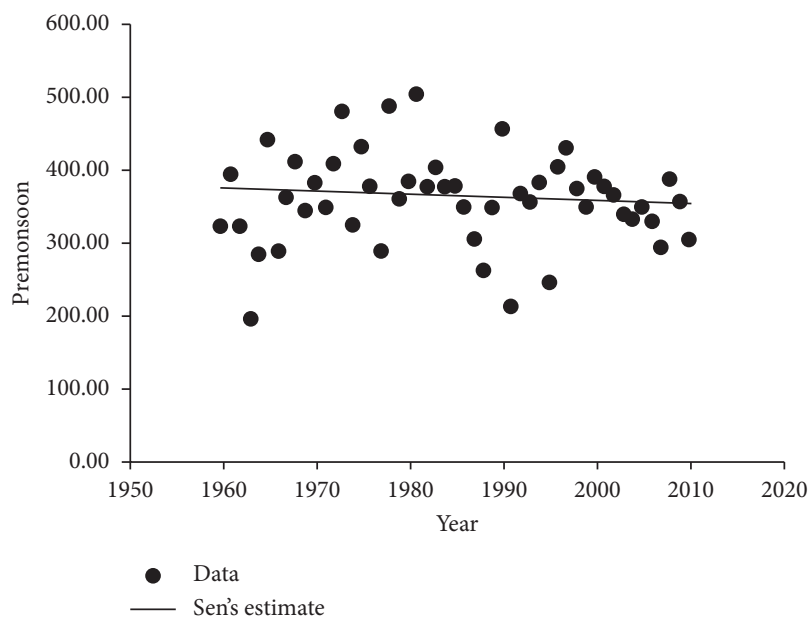

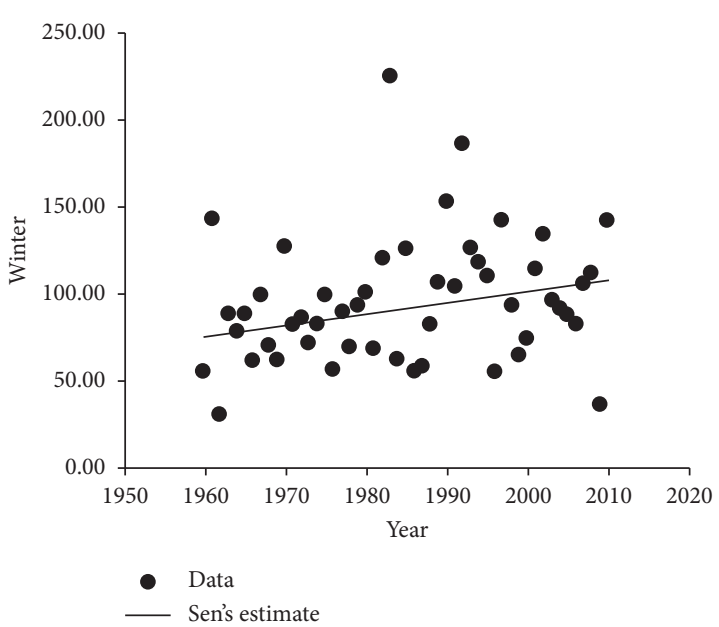

(b)

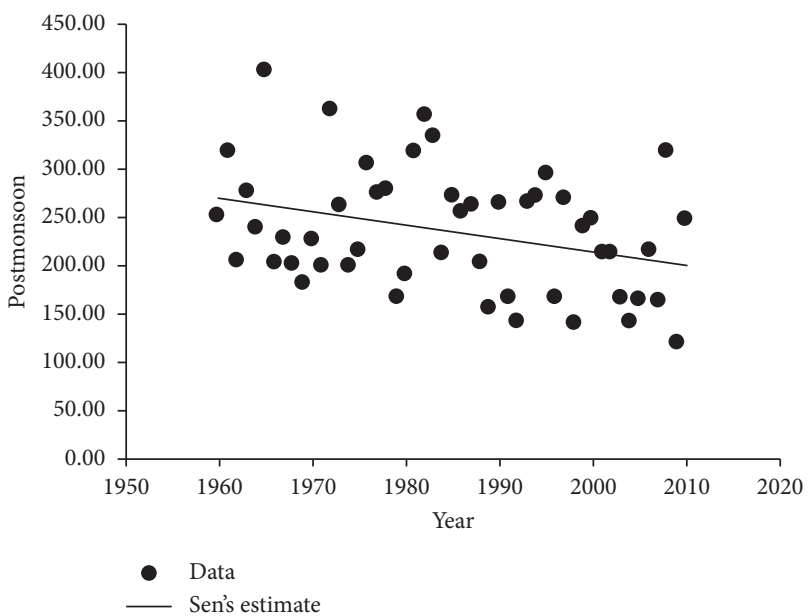

(d)

(c)

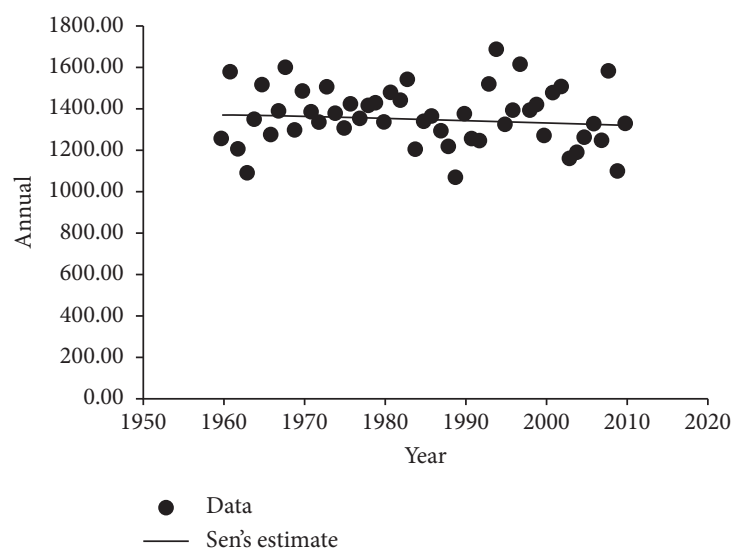

(e)

Figure 4: (a-e) Sen's slope estimator for annual and seasonal precipitation.

CM5A-LR, MIROC-ESM-CHEM, and NorESM1-M) from ISI-MIP (Intersectoral Impact Model Intercomparison Project). Future Global Climate Datasets are available for (2006-2099) and historical GCMs (1950-2005) shown in Figure 7 as a baseline. This study analyzed future daily precipitation GCMs data over the Xijiang River Basin for the period of 2020-2099. Raw GCMs data were statistically downscaled using Bias Correction Special Disaggregation (BCSD) applied to remove Bias. GCMs future precipitation statistics are summarized in Table 3.

The historical precipitation over the Xijiang River Basin showed similar characteristics with that of observed 
TABLE 2: MK Test $Z$ and Sen's slope estimator $Q$ of annual and seasonal observed rainfall at Xijiang Basin.

\begin{tabular}{|c|c|c|c|c|c|c|c|c|c|c|c|}
\hline \multirow{2}{*}{ Station name } & \multirow{2}{*}{ Station number } & \multicolumn{2}{|c|}{ Annual } & \multicolumn{2}{|c|}{ Monsoon } & \multicolumn{2}{|c|}{ Winter } & \multicolumn{2}{|c|}{ Premonsoon } & \multicolumn{2}{|c|}{ Postmonsoon } \\
\hline & & $Z$ & Q & $Z$ & Q & $Z$ & $Q$ & $Z$ & $Q$ & $Z$ & $Q$ \\
\hline Wei Ning & 56691 & -1.67 & -2.84 & -0.67 & -0.640 & 3.04 & 0.324 & -0.62 & -0.358 & -1.85 & -1.276 \\
\hline Zhanyi & 56786 & -1.72 & -2.989 & -2.02 & -2.917 & 3.54 & 0.904 & 0.96 & 0.530 & -1.92 & -1.625 \\
\hline Panxian & 56793 & -1.09 & -2.473 & -0.70 & -1.080 & 2.58 & 0.644 & 0.02 & 0.029 & -2.69 & -2.650 \\
\hline Yuxi & 56875 & 0.00 & 0.018 & -0.08 & -0.072 & 1.80 & 0.452 & 1.59 & 0.885 & -1.15 & -0.783 \\
\hline Luxi & 56886 & -1.95 & -3.014 & -2.20 & -1.779 & 0.99 & 0.225 & 0.75 & 0.456 & -1.93 & -1.432 \\
\hline Mengzi & 56985 & -0.10 & -0.150 & -0.76 & -0.820 & 0.80 & 0.236 & 1.54 & 0.941 & -0.80 & -0.427 \\
\hline Anshun & 57806 & -1.35 & -2.600 & 0.16 & 0.306 & 1.30 & 0.311 & -1.61 & -1.729 & -1.58 & -1.429 \\
\hline Xingyi & 57902 & -0.29 & -0.741 & 1.11 & 1.421 & 1.26 & 0.293 & -0.62 & -0.659 & -1.54 & -1.578 \\
\hline Wangmo & 57906 & 0.73 & 1.863 & 0.58 & 1.121 & 0.04 & 0.011 & -0.70 & -0.576 & -0.19 & -0.140 \\
\hline Luodian & 57916 & 0.67 & 1.345 & 0.57 & 0.994 & 0.84 & 0.219 & 0.89 & 0.869 & -0.92 & -0.715 \\
\hline Dushan & 57922 & 0.16 & 0.314 & 0.57 & 0.900 & 1.72 & 0.739 & 0.17 & 0.200 & -1.88 & -1.835 \\
\hline Rongjiang & 57932 & 0.67 & 1.596 & 0.79 & 1.345 & 2.49 & 1.027 & 0.87 & 0.750 & -0.79 & -0.648 \\
\hline Rongan & 57947 & -0.06 & -0.075 & 1.30 & 3.461 & 1.76 & 1.281 & -0.73 & -0.900 & -2.40 & -2.340 \\
\hline Guilin & 57957 & 0.54 & 2.029 & 1.84 & 4.550 & 1.69 & 1.529 & -0.60 & -1.095 & -1.97 & -1.850 \\
\hline Guangnan & 59007 & -1.36 & -2.600 & -0.84 & -1.443 & 0.81 & 0.186 & -0.88 & -0.680 & -2.81 & -1.748 \\
\hline Fengshan & 59021 & -0.13 & -0.408 & 0.19 & 0.484 & 2.15 & 8.000 & -0.37 & -0.411 & -1.25 & -1.089 \\
\hline Hechi & 59023 & -0.83 & -2.338 & -0.97 & -1.500 & 1.64 & 0.796 & -0.76 & -1.229 & -2.08 & -1.623 \\
\hline Duan & 59037 & -0.52 & -1.419 & -0.23 & -0.521 & 0.96 & 0.540 & 0.06 & 0.089 & -1.61 & -1.537 \\
\hline Liuzhou & 59046 & 0.06 & 0.396 & 0.32 & 0.896 & 1.36 & 0.822 & -0.18 & -0.237 & -1.80 & -1.503 \\
\hline Mengshan & 59058 & 0.76 & 2.403 & 1.48 & 3.708 & 1.35 & 1.127 & -0.82 & -0.980 & -2.42 & -2.092 \\
\hline Hezhou & 59065 & 0.30 & 0.897 & 0.47 & 0.709 & 0.74 & 0.678 & -0.19 & -0.253 & -1.45 & -1.309 \\
\hline Napo & 59209 & -1.53 & -2.926 & -0.96 & -0.920 & 0.58 & 0.182 & -0.26 & -0.272 & -1.45 & -1.488 \\
\hline Baise & 59211 & -0.37 & -0.783 & -0.41 & -0.635 & 1.23 & 0.293 & 0.19 & 0.233 & -0.86 & -0.817 \\
\hline Jingxi & 59218 & 0.65 & 1.611 & 0.29 & 0.640 & 1.56 & 0.641 & 0.19 & 0.173 & -0.31 & -0.250 \\
\hline Laibin & 59242 & -1.01 & -2.827 & -0.75 & -1.408 & 0.85 & 0.490 & -0.32 & -0.333 & -0.85 & -0.535 \\
\hline Guiping & 59254 & 0.75 & 1.768 & 0.63 & 1.425 & 1.08 & 0.897 & -0.90 & -1.576 & -1.01 & -1.208 \\
\hline Wuzhou & 59265 & -0.84 & -1.897 & 0.24 & 0.553 & 1.02 & 0.692 & -1.49 & -1.932 & -1.59 & -1.572 \\
\hline Gaoyao & 59278 & -0.42 & -1.609 & -1.02 & -1.600 & 1.06 & 0.570 & 0.54 & 0.942 & -0.83 & -1.113 \\
\hline Longzhou & 59417 & -1.30 & -3.087 & -0.68 & -1.236 & 0.91 & 0.295 & -0.65 & -0.586 & -1.88 & -1.513 \\
\hline Nanning & 59431 & -1.01 & -2.226 & 0.00 & -0.032 & 0.41 & 0.158 & -1.59 & -1.422 & -1.40 & -1.355 \\
\hline Xinyi & 59456 & -0.34 & -1.733 & 0.10 & 0.193 & 0.47 & 0.116 & -0.23 & -0.376 & -1.28 & -1.380 \\
\hline Louding & 59462 & 0.00 & -0.023 & -0.26 & -0.432 & 0.52 & 0.380 & 0.41 & 0.689 & -0.90 & -1.253 \\
\hline
\end{tabular}

historical precipitation with an annual mean precipitation of $1500 \mathrm{~mm}$. Skewness is positive while the dataset is lighttailed distribution.

3.4.1. Future Projections in Annual and Seasonal Rainfall. There are considerable uncertainties associated with projecting changes for future rainfall projections. These uncertainties may rise from different GCM outputs and scenarios. The three assumptions in these GCMs outputs are as follows: predictors are variables of importance and are realistically modeled by the host GCM; the empirical relationship is valid under changing climatic conditions; and the predictors employed fully represent the climate change signal [60]. In this study, five GCMs outputs for all scenarios were analyzed and the bias was removed based on bias correction spatial disaggregation (BCSD) method.

Historical GCMs output in Table 4 has similar trends recorded by observed rainfall in Table 5 . Four out of five GCMs in Figure 8 have decreasing trends in average annual and seasonal historical precipitation while NoerESM1-M has a slightly increasing trend. Climate Research Unit (CRU-TS3.1) historical data Table 4 which was baseline data for bias correction also have decreasing trends. Annual mean precipitation output for future scenarios has likely to be inclined trends except for IPSL-CM5A-LR which showed the contrast in trends and all scenarios have negative $\mathrm{MK} \mathrm{Z}$ statistics and negative Sen's slope $Q$ magnitude marked in Table 6. Seasonal precipitation will likely have increased trends in rainfall in future scenarios. Few scenarios have negative trends that prove the existence of uncertainties in GCMs output.

3.5. Decadewise Annual and Seasonal Rainfall. Decadewise annual and seasonal observed rainfall and mean of the future projections under all four scenarios depicted in Figures 9 and 10, respectively. In the 2010s, the basin received the lowest annual rainfall of $1313.50 \mathrm{~mm}$ while the predecade 2000s received the highest rainfall of $1407.2 \mathrm{~mm}$. The arithmetic mean of annual precipitation for the past 51 years (1960-2010) was $1360 \mathrm{~mm}$. Considering this value as a baseline RCP-2.6 predicts change of $9.2 \%$, RCP- 4.5 predicts change of $8.04 \%$, and RCP-6.0 will likely observe the highest change of $9.79 \%$ and RCP-8.5 with the lowest change of $7.1 \%$, as reported in Table 7 .

Decadal future projections for five GCMs under all four emission scenarios presented in Figure 10 predict that 2050 s 


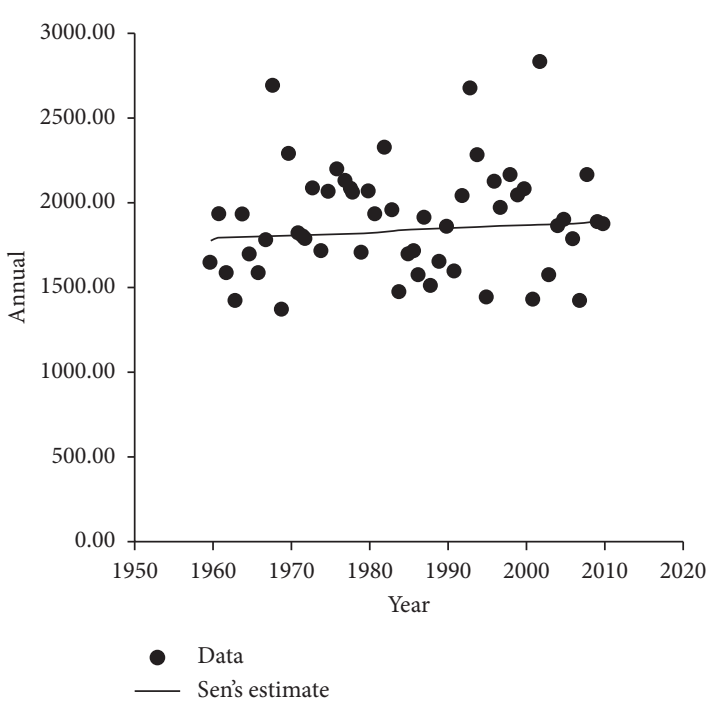

(a)

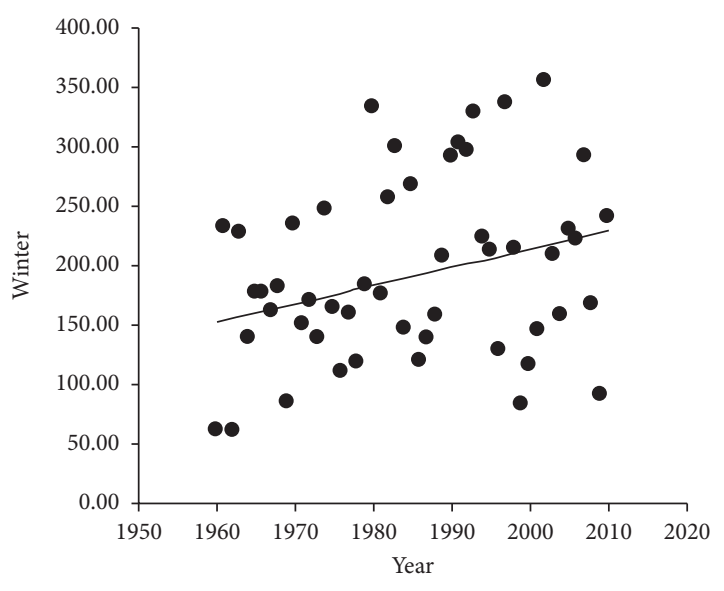

- Data

Sen's estimate

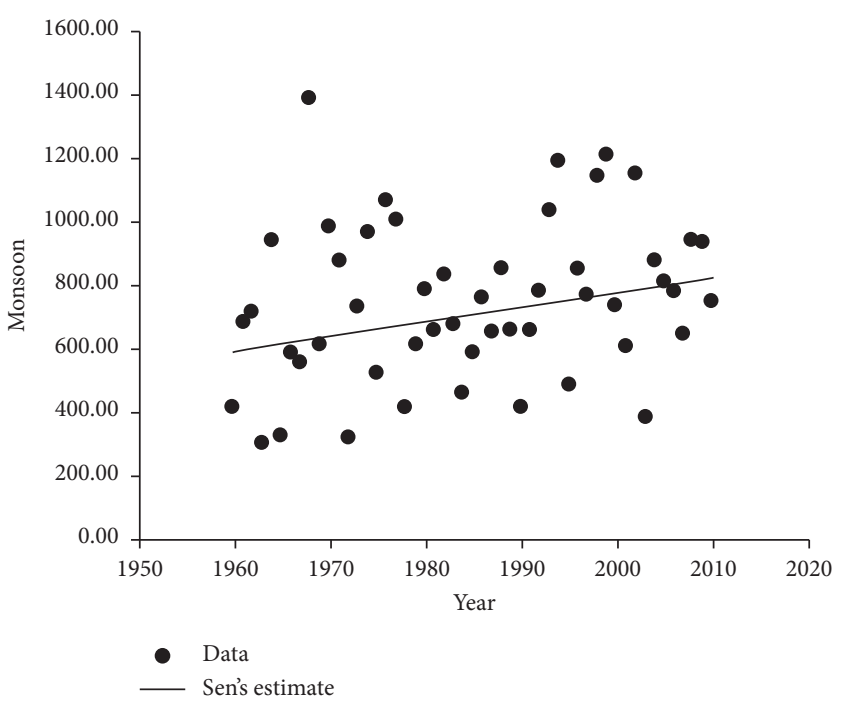

(b)

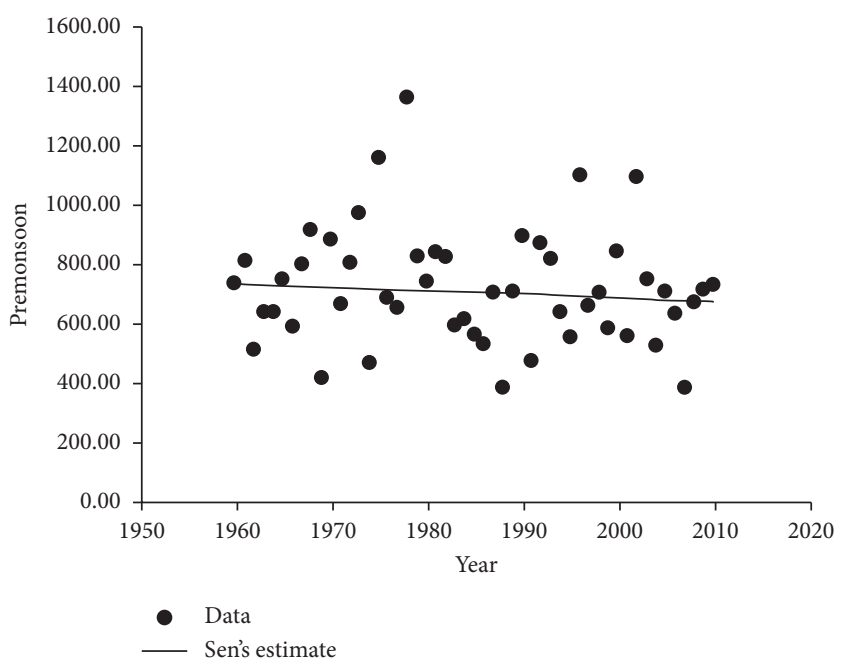

(d)

(c)

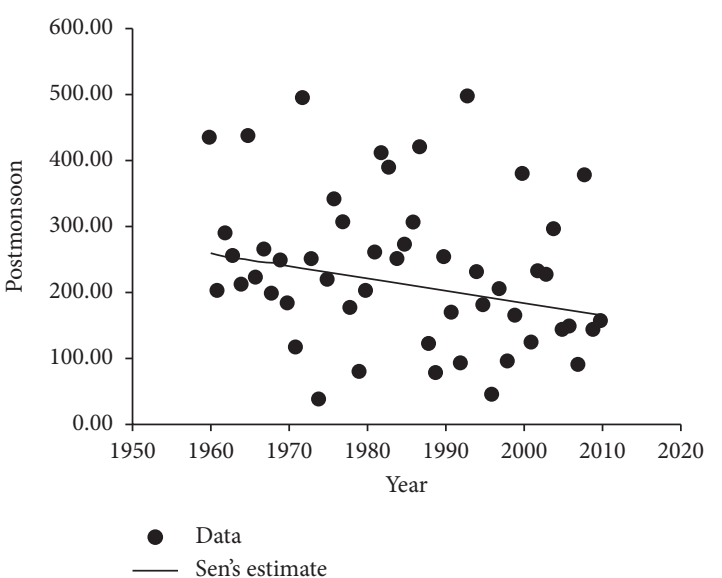

(e)

FIgURE 5: (a-e) Sen's slope estimator of Guilin station (highest average annual rainfall $1883.33 \mathrm{~mm}$ ). 


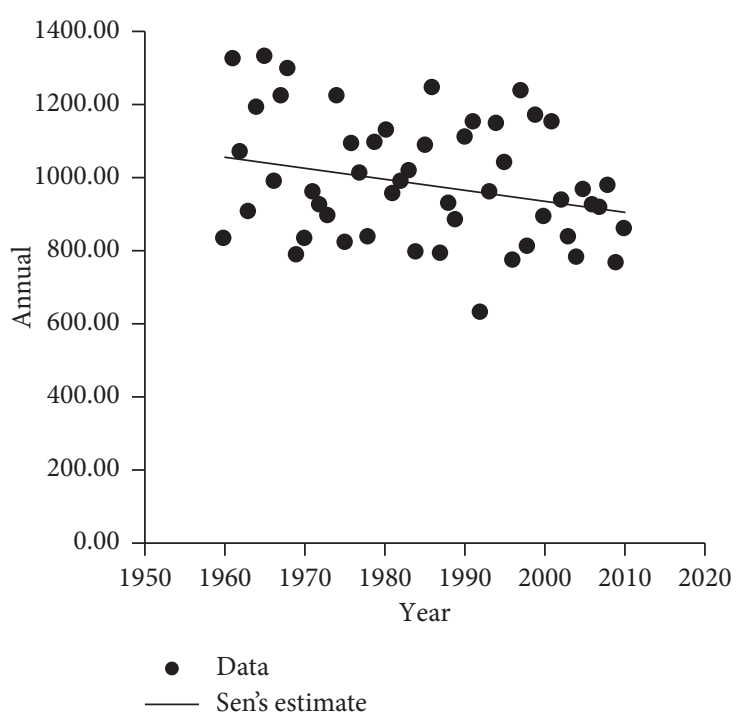

(a)

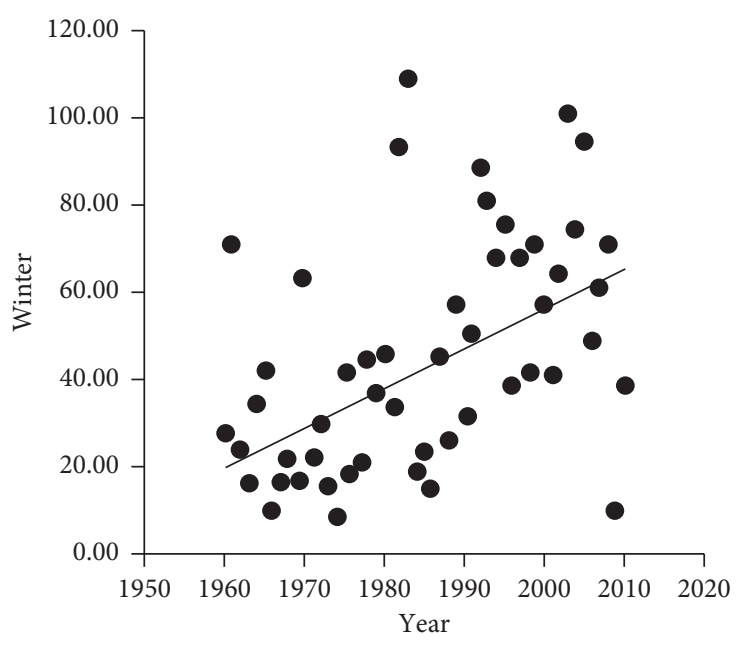

- Data

Sen's estimate

(c)

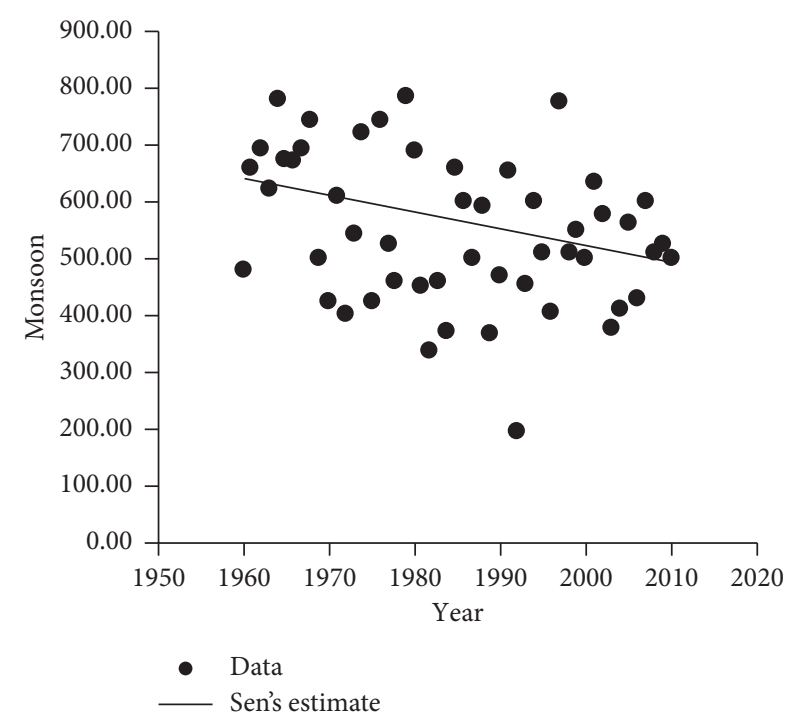

(b)

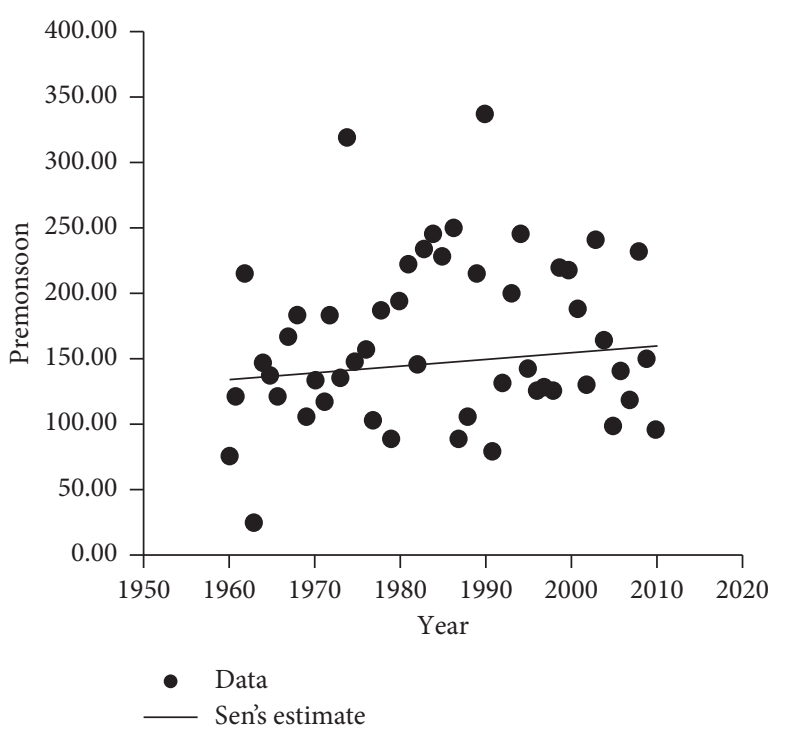

(d)

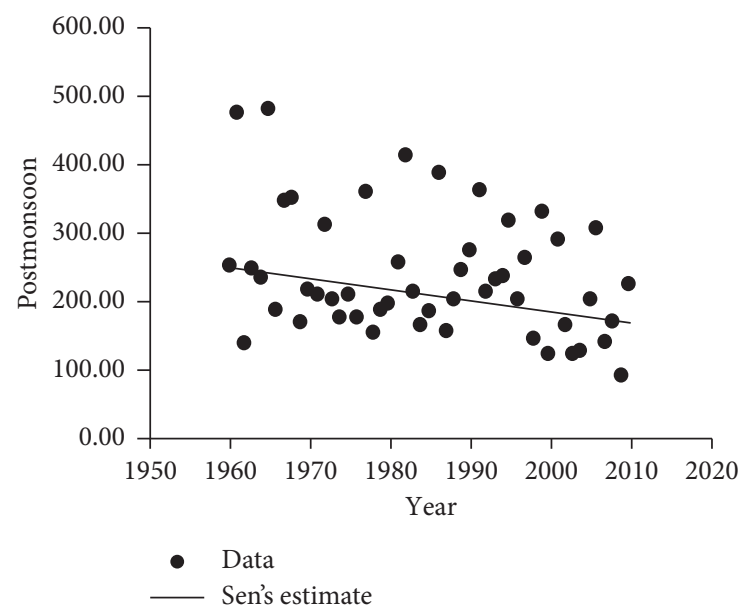

(e)

Figure 6: (a-e) Sen's slope estimator of Zhanyi station (lowest average annual rainfall $867.1 \mathrm{~mm}$ ). 


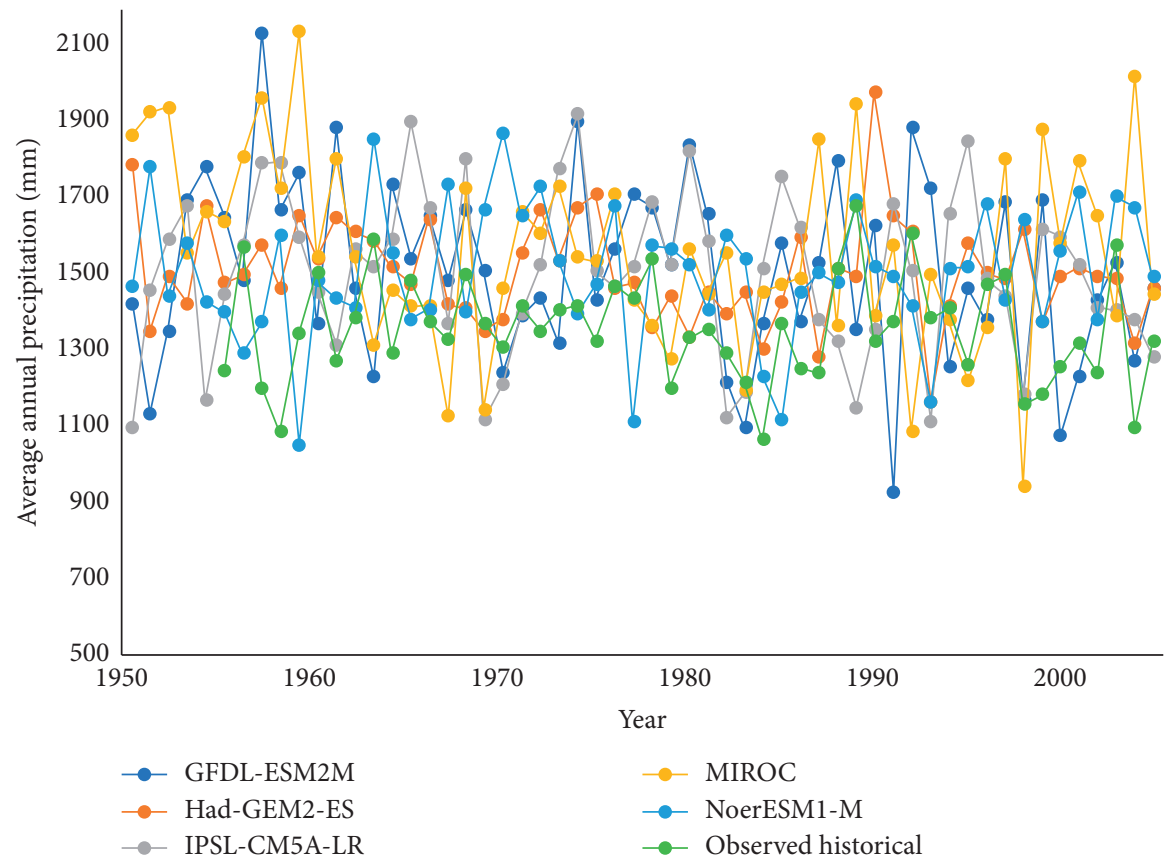

Figure 7: Annual average precipitation of historical GCMs and observed historical precipitation.

TABle 3: Annual precipitation statistics of Global Climate Models (GCMs) over the study area.

\begin{tabular}{|c|c|c|c|c|c|c|c|}
\hline ISI-MIP model & Scenarios & Period & Mean $(\mathrm{mm})$ & STD & $\mathrm{C}_{s}$ & $\mathrm{C}_{k}$ & $\mathrm{C}_{v}$ \\
\hline \multirow{5}{*}{ GFDL-ESM2M } & Historical & $1950-2005$ & 1510.2 & 239.9 & 0.2 & -0.1 & 15.9 \\
\hline & RCP-2.6 & 2020-2099 & 1498.3 & 225.41 & 0.38 & 0.0 & 15.0 \\
\hline & RCP-4.5 & 2020-2099 & 1480.6 & 241.19 & -0.08 & 0.0 & 16.3 \\
\hline & RCP- 6.0 & 2020-2099 & 1505.7 & 208.80 & -0.25 & 0.86 & 13.9 \\
\hline & RCP-8.5 & 2020-2099 & 1463.0 & 230.42 & 0.19 & -0.6 & 15.7 \\
\hline \multirow{5}{*}{ Had-GEM2-ES } & Historical & $1950-2005$ & 1507.3 & 136.4 & 0.3 & 1.8 & 9.10 \\
\hline & RCP-2.6 & 2020-2099 & 1579.9 & 174.61 & 0.10 & -0.4 & 11.1 \\
\hline & RCP-4.5 & $2020-2099$ & 1538.3 & 168.88 & 0.45 & -0.4 & 11.0 \\
\hline & RCP-6.0 & 2020-2099 & 1547.2 & 187.85 & -0.09 & 0.85 & 12.1 \\
\hline & RCP-8.5 & $2020-2099$ & 1615.1 & 189.56 & -0.04 & -0.52 & 11.7 \\
\hline \multirow{5}{*}{ IPSL-CM5A-LR } & Historical & 1950-2005 & 1502.4 & 215.3 & -0.2 & -0.60 & 14.3 \\
\hline & RCP-2.6 & $2020-2099$ & 1408.2 & 204.94 & 0.06 & 1.077 & 14.6 \\
\hline & RCP-4.5 & 2020-2099 & 1511.2 & 223.05 & 0.39 & -0.2 & 14.76 \\
\hline & RCP-6.0 & 2020-2099 & 1447.7 & 219.98 & 0.19 & 0.78 & 15.19 \\
\hline & RCP-8.5 & 2020-2099 & 1329.5 & 192.57 & 0.33 & 0.1 & 14.5 \\
\hline \multirow{5}{*}{ MIROC } & Historical & 1950-2005 & 1563.3 & 252.3 & 0.2 & -0.2 & 16.1 \\
\hline & RCP-2.6 & 2020-2099 & 1491.2 & 227.55 & 0.06 & 2.0 & 15.3 \\
\hline & RCP-4.5 & 2020-2099 & 1501.3 & 242.47 & 0.07 & -0.1 & 16.2 \\
\hline & RCP-6.0 & 2020-2099 & 1382.0 & 218.40 & 0.26 & -0.642 & 15.8 \\
\hline & RCP-8.5 & 2020-2099 & 1510.3 & 223.60 & 0.06 & -0.05 & 14.8 \\
\hline \multirow{5}{*}{ NoerESM1-M } & Historical & $1950-2005$ & 1505.4 & 174.6 & 0.1 & 0.5 & 11.6 \\
\hline & RCP-2.6 & $2020-2099$ & 1616.5 & 198.33 & -0.3 & -0.7 & 12.3 \\
\hline & RCP-4.5 & 2020-2099 & 1633.9 & 215.10 & 0.5 & -0.2 & 13.2 \\
\hline & RCP-6.0 & 2020-2099 & 1491.4 & 184.0 & 0.5 & 0.1 & 12.3 \\
\hline & RCP- 8.5 & $2020-2099$ & 1559.3 & 184.70 & 0.50 & 0.2 & 11.80 \\
\hline CRU & Observed (historical) & 1970-2006 & 1501.9 & 133.0 & 0.70 & & 8.90 \\
\hline
\end{tabular}

will likely receive the highest amount of rainfall $1541.26 \mathrm{~mm}$ while the 2040s will likely observe the lowest value of $1449.22 \mathrm{~mm}$. The middle of the $21^{\text {st }}$ century will likely observe the lowest and highest rainfall in consecutive decades.

\section{Discussion}

The present study is an attempt to evaluate the spatial and temporal variability trends in observed rainfall (1960-2010) 
TABLe 4: MK test $Z$ and Sen's slope estimator $Q$ of annual and seasonal future rainfall at the Xijiang Basin.

\begin{tabular}{|c|c|c|c|c|c|c|c|c|c|c|c|c|}
\hline \multirow{2}{*}{ ISI-MIP model } & \multirow{2}{*}{ Scenarios } & \multirow{2}{*}{ Period } & \multicolumn{2}{|c|}{ Annual } & \multicolumn{2}{|c|}{ Monsoon } & \multicolumn{2}{|c|}{ Winter } & \multicolumn{2}{|c|}{ Premonsoon } & \multicolumn{2}{|c|}{ Postmonsoon } \\
\hline & & & $Z$ & $Q$ & $Z$ & $Q$ & $Z$ & Q & $Z$ & $Q$ & Z & Q \\
\hline \multirow{5}{*}{ GFDL-ESM2M } & Historical & 1950-2005 & -1.52 & -3.17 & -1.51 & -1.26 & -0.76 & -0.23 & -0.76 & -0.86 & -1.31 & -1.35 \\
\hline & RCP-2.6 & 2020-2099 & -0.37 & -0.37 & 0.19 & 0.117 & 0.05 & 0.018 & -0.18 & -0.09 & -0.67 & -0.34 \\
\hline & RCP-4.5 & 2020-2099 & 0.64 & 0.73 & -0.02 & -0.02 & 0.18 & 0.05 & -1.12 & -0.55 & 1.57 & 0.89 \\
\hline & RCP-6.0 & 2020-2099 & 1.35 & 1.22 & 2.16 & 1.21 & 1.40 & 0.40 & 0.11 & 0.06 & -0.05 & -0.03 \\
\hline & RCP-8.5 & 2020-2099 & -1.02 & -1.37 & 1.28 & 0.84 & -2.16 & -0.56 & -2.46 & -1.14 & 0.33 & 0.23 \\
\hline \multirow{5}{*}{ Had-GEM2-ES } & Historical & $1950-2005$ & -1.51 & -1.59 & -1.15 & -0.71 & -2.30 & -0.44 & -1.24 & -1.04 & 1.21 & 0.63 \\
\hline & RCP-2.6 & 2020-2099 & 1.67 & 1.55 & 1.29 & 0.68 & -0.12 & -0.02 & 1.04 & 0.39 & 0.75 & 0.37 \\
\hline & RCP-4.5 & 2020-2099 & 2.29 & 2.02 & 1.64 & 0.87 & 3.00 & 0.38 & 0.68 & 0.29 & 1.18 & 0.53 \\
\hline & RCP-6.0 & 2020-2099 & 3.08 & 2.45 & 3.10 & 1.65 & 1.08 & 0.16 & -0.89 & -0.31 & 2.41 & 1.11 \\
\hline & RCP-8.5 & 2020-2099 & 3.72 & 3.26 & 1.70 & 0.82 & 3.29 & 0.49 & -0.84 & -0.33 & 3.71 & 2.04 \\
\hline \multirow{5}{*}{ IPSL-CM5A-LR } & Historical & 1950-2005 & -1.00 & -1.98 & 0.2 & 0.20 & -0.95 & -0.61 & -0.09 & -0.11 & -1.08 & -0.95 \\
\hline & RCP-2.6 & 2020-2099 & -0.84 & -0.89 & -0.37 & -0.21 & 0.17 & 0.05 & -0.96 & -0.33 & -0.32 & -0.21 \\
\hline & RCP-4.5 & 2020-2099 & -0.32 & -0.46 & 1.15 & 0.54 & -1.95 & -0.37 & -1.94 & -0.94 & 0.74 & 0.42 \\
\hline & RCP-6.0 & 2020-2099 & -0.76 & -0.90 & -0.30 & -0.14 & -1.23 & -0.37 & -1.20 & -0.58 & 0.65 & 0.37 \\
\hline & RCP-8.5 & 2020-2099 & -0.54 & -0.44 & 1.52 & 0.78 & -3.10 & -0.56 & -1.97 & -0.78 & 0.47 & 0.21 \\
\hline \multirow{5}{*}{ MIROC } & Historical & & -2.04 & -4.85 & -2.14 & -2.82 & -1.18 & -0.64 & -0.93 & -0.74 & 0.09 & 0.08 \\
\hline & RCP-2.6 & 2020-2099 & 1.72 & 1.84 & 0.95 & 0.69 & 1.52 & 0.46 & 0.16 & 0.12 & 0.60 & 0.31 \\
\hline & RCP-4.5 & 2020-2099 & 2.51 & 3.24 & 0.61 & 0.55 & 0.98 & 0.34 & 1.75 & 0.95 & 1.20 & 0.53 \\
\hline & RCP-6.0 & 2020-2099 & 0.90 & 1.06 & 0.02 & 0.03 & 1.81 & 0.41 & 0.64 & 0.31 & 0.51 & 0.21 \\
\hline & RCP-8.5 & $2020-2099$ & 2.32 & 2.75 & 2.27 & 1.96 & 0.75 & 0.26 & 1.87 & 0.94 & -1.83 & -0.83 \\
\hline \multirow{5}{*}{ NoerESM1-M } & Historical & $1950-2005$ & 0.60 & 0.94 & 1.29 & 1.09 & -1.01 & -0.30 & -0.29 & -0.21 & -0.66 & -0.44 \\
\hline & RCP-2.6 & 2020-2099 & -0.09 & -0.07 & -0.28 & -0.25 & -0.10 & -0.03 & 1.37 & 0.58 & -0.81 & -0.49 \\
\hline & RCP-4.5 & $2020-2099$ & 3.69 & 4.28 & 3.27 & 2.531 & -0.55 & -0.15 & 2.35 & 1.01 & 0.63 & 0.28 \\
\hline & RCP-6.0 & 2020-2099 & 2.19 & 2.04 & 1.84 & 1.38 & 0.15 & 0.02 & 1.61 & 0.51 & 1.15 & 0.52 \\
\hline & RCP-8.5 & $2020-2099$ & 3.88 & 3.36 & 0.80 & 0.45 & 1.87 & 0.48 & 3.07 & 1.12 & 2.56 & 1.23 \\
\hline CRU & Observed (historical) & 1970-2006 & -0.20 & -0.35 & 1.11 & 2.08 & 0.69 & 0.27 & -0.56 & -0.61 & -1.45 & -1.45 \\
\hline
\end{tabular}

TABLE 5: Mann-Kendall test $Z$ trend statistics of historical annual and seasonal average precipitation.

\begin{tabular}{|c|c|c|c|c|c|c|}
\hline Station name & Station number & Annual & Monsoon & Winter & Premonsoon & Postmonsoon \\
\hline Wei Ning & 56691 & $m$ & $m$ & m & $m$ & $m$ \\
\hline Zhanyi & 56786 & $m$ & $m$ & w & 5 & $m$ \\
\hline Panxian & 56793 & $m$ & $m$ & m & & $m$ \\
\hline Yuxi & 56875 & $\underline{m}$ & $m$ & m & $\mu^{x}$ & 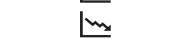 \\
\hline Luxi & 56886 & $m$ & $m$ & m & w & $m$ \\
\hline Mengzi & 56985 & $m$ & $m$ & w & w & $m$ \\
\hline Anshun & 57806 & $m$ & $\underline{m}$ & w & Ex & 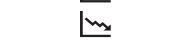 \\
\hline Xingyi & 57902 & $m$ & w & w & $m$ & $m$ \\
\hline Wangmo & 57906 & 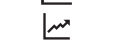 & س & w & $m$ & $m$ \\
\hline Luodian & 57916 & Lx & w & w & $w^{n}$ & $m$ \\
\hline Dushan & 57922 & $m$ & w & w & $\omega^{x}$ & $m$ \\
\hline Rongjiang & 57932 & $m$ & N & w & $\omega^{x}$ & $m$ \\
\hline Rongan & 57947 & $m$ & w & w & $m$ & $m$ \\
\hline Guilin & 57957 & 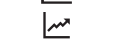 & w & w & $m$ & $m$ \\
\hline Guangnan & 59007 & $m$ & $m$ & w & $m$ & $m$ \\
\hline Fengshan & 59021 & $m$ & m & w & $m$ & $m$ \\
\hline Hechi & 59023 & 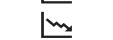 & $m$ & m & $\min$ & $m$ \\
\hline Duan & 59037 & $m$ & $m$ & w & w & $m$ \\
\hline Liuzhou & 59046 & w & w & w & $m$ & $m$ \\
\hline Mengshan & 59058 & m & m & w & $m$ & $\min$ \\
\hline Hezhou & 59065 & Lx & w & w & $m$ & $m$ \\
\hline Napo & 59209 & $m$ & $m$ & w & $m$ & $m$ \\
\hline Baise & 59211 & $m$ & $m$ & m & w & $m$ \\
\hline Jingxi & 59218 & w & w & w & $\omega^{n}$ & $m$ \\
\hline Laibin & 59242 & $m$ & $m$ & w & $m$ & $m$ \\
\hline Guiping & 59254 & 5 & 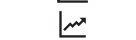 & m & 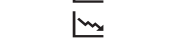 & 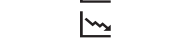 \\
\hline Wuzhou & 59265 & $m$ & 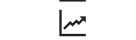 & m & $m$ & $m$ \\
\hline Gaoyao & 59278 & $m$ & $m$ & w & 5 & $m$ \\
\hline Longzhou & 59417 & $m$ & $m$ & w & $m$ & $m$ \\
\hline Nanning & 59431 & $m$ & $m$ & w & $m$ & $m$ \\
\hline Xinyi & 59456 & $m$ & w & w & $m$ & $m$ \\
\hline Louding & 59462 & $\underline{m}$ & $m$ & w & Ln & $m$ \\
\hline
\end{tabular}



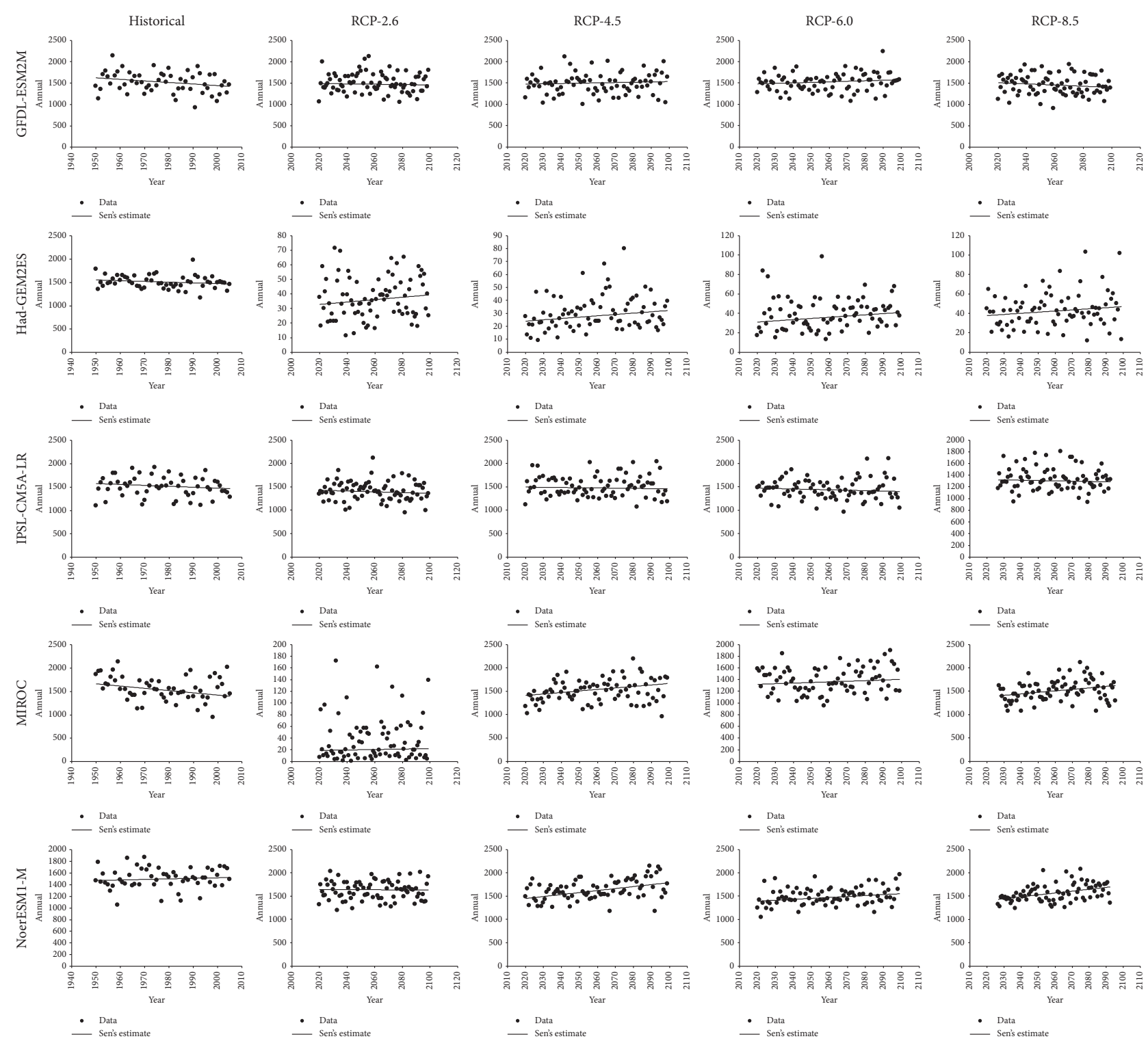

Figure 8: Historical, RCP-2.6, RCP-4.5, RCP-6.0, and RCP-8.5 MK Z statistics and Sen's slope estimator.

and future rainfall analyzing Global Climate Models (GCMs) datasets for historical period (1950-2006) and future (2020-2099) over the Xijiang River Basin. The analysis and detection of trends in the annual, monsoon, winter, premonsoon, and postmonsoon seasons have been carried out in 32 weather stations of the Xijiang River Basin. The past century rainfall behavior observed the low variations in their anomaly. Based on the Mann-Kendall test and Sen's slope estimator annual, premonsoon and postmonsoon average rainfall have decreasing trends while all-weather stations observed increasing trends in the winter season. Monsoon season observed a slight increase with an average $Q$ value of 0.177 . Similar results were achieved by Zhang et al. [22]. They found increased number of rainy days in the Pearl River Basin. The coefficient of variation for average annual rainfall at Dushan station is the lowest at $13.1 \%$ while at Guangnan station CV is $22.2 \%$. The main findings of this study were the low precipitation and declining trends at higher altitudes in the upper Xijiang Basin while the lower Xijiang Basin at lower altitudes recorded high precipitation and trends were inclined. This is consistent with the study by Wang et al. [61]. Historical precipitation for four out of five GCMs observing decreasing trends having average Sen's slope magnitude $Q-1.09$. NoerESM1-M observed a slight increase in annual average historical precipitation with a $Q$ value of 0.77 . The results are further validated by historical precipitation recorded by the Climate Research Unit (CRUTS-3.1). CRU annual, premonsoon, and postmonsoon mean historical precipitation have decreasing trends while monsoon and winter seasons have increasing trends. The results are further supported by several studies $[35,38]$. The lowest scenario RCP-2.6 showed variation in the trends. HadGEM2ES and MIROC will likely to observe increasing trends while the rest of the three GCMs have negative trends in annual precipitation. RCP-4.5 recorded positive trends except for IPSL-CM5A-LR for annual precipitation. RCP-6.0 
TABle 6: Mann-Kendall test $Z$ trend statistics of future (GCMs) annual and seasonal average precipitation.

\begin{tabular}{|c|c|c|c|c|c|c|c|}
\hline ISI-MIP model & Scenarios & Period & Annual & Monsoon & Winter & Prmonsoon & Postmonsoon \\
\hline \multirow{5}{*}{ GFDL-ESM2M } & Historical & 1950-2005 & $m$ & $m$ & $m$ & $m_{x}$ & $m$ \\
\hline & RCP-2.6 & 2020-2099 & $m$ & $\underline{m}$ & 5 & $m$ & $m$ \\
\hline & RCP-4.5 & 2020-2099 & m & $m$ & w & $m$ & $\mu^{x}$ \\
\hline & RCP-6.0 & 2020-2099 & w & Ln & w & 5 & $m$ \\
\hline & RCP-8.5 & 2020-2099 & $m$ & $\mu^{x}$ & wn & $m$ & $m$ \\
\hline \multirow{5}{*}{ Had-GEM2-ES } & Historical & 1950-2005 & $m$ & $m$ & En & $m_{m}$ & $\omega^{x}$ \\
\hline & RCP-2.6 & 2020-2099 & L & w & w & Lx & L \\
\hline & RCP-4.5 & 2020-2099 & $\omega^{x}$ & $\omega^{x}$ & $\omega^{x}$ & 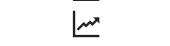 & $\omega^{x}$ \\
\hline & RCP-6.0 & 2020-2099 & w & m & w & $m$ & w \\
\hline & RCP-8.5 & 2020-2099 & $\omega^{x}$ & $\omega^{x}$ & En & $m$ & $\omega^{x}$ \\
\hline \multirow{5}{*}{ IPSL-CM5A-LR } & Historical & 1950-2005 & $m$ & $\omega^{x}$ & 5 & $m$ & $m$ \\
\hline & RCP-2.6 & 2020-2099 & $m$ & $m$ & $\bar{n}$ & $m$ & $m$ \\
\hline & RCP-4.5 & 2020-2099 & $m$ & m & w & $m$ & $\omega^{m}$ \\
\hline & RCP-6.0 & 2020-2099 & $m$ & $m$ & 5 & $m$ & $\left.\right|^{\infty}$ \\
\hline & RCP-8.5 & 2020-2099 & $m$ & L & Ln & $m$ & L \\
\hline \multirow{5}{*}{ MIROC } & Historical & 1950-2005 & $m$ & $m$ & 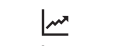 & $m$ & $\underline{m}$ \\
\hline & RCP-2.6 & 2020-2099 & $m$ & Ln & w & 5 & L \\
\hline & RCP-4.5 & 2020-2099 & 幽 & Ler & $\underline{m}$ & m & $\mu^{x}$ \\
\hline & RCP-6.0 & 2020-2099 & w & Ln & w & m & Ln \\
\hline & RCP-8.5 & 2020-2099 & m & Ln & En & m & $m$ \\
\hline \multirow{5}{*}{ NoerESM1-M } & Historical & $1950-2005$ & w & Ln & Ex & $m$ & $m$ \\
\hline & RCP-2.6 & 2020-2099 & $m$ & $m$ & 幽 & 监 & $m$ \\
\hline & RCP-4.5 & 2020-2099 & m & m & m & m & Ln \\
\hline & RCP-6.0 & 2020-2099 & س & 要 & w & w & 要 \\
\hline & RCP- 8.5 & 2020-2099 & m & m & m & m & $\omega^{x}$ \\
\hline CRU & Observed (historical) & 1970-2006 & $m$ & 幽 & $\ln ^{x}$ & $m$ & $m$ \\
\hline
\end{tabular}

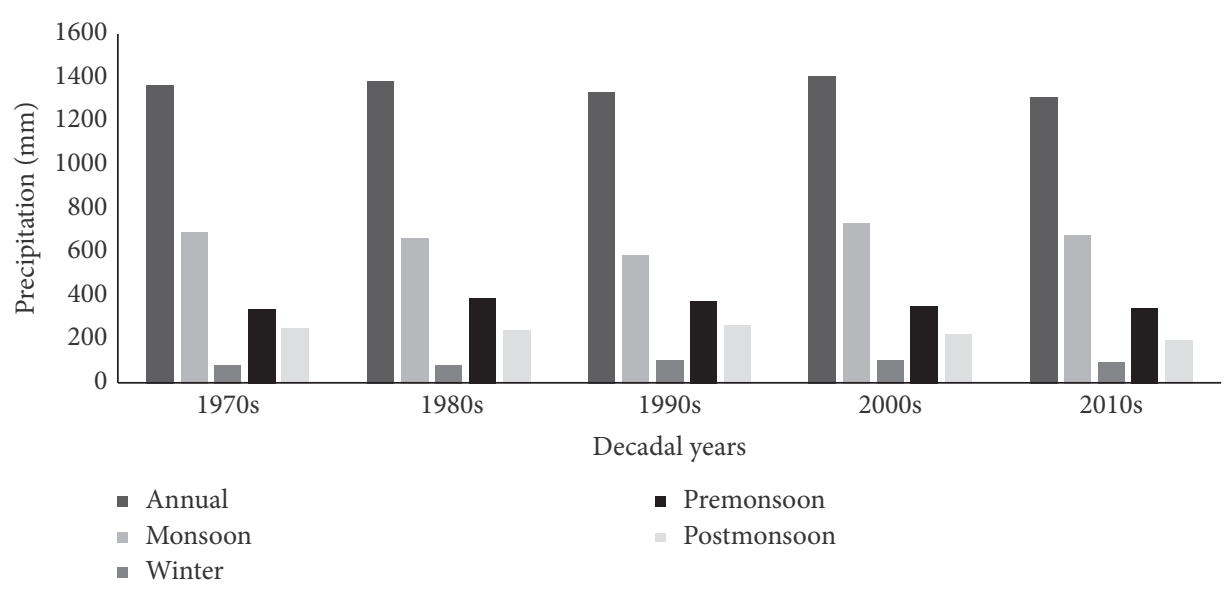

FIGURE 9: Decadal segmentation of the annual and seasonal observed rainfall.

follows the negative trends, positive trends observed in HadGEM2ES and MIROC. The highest scenario RCP-8.5 has likely to be increasing trends in annual precipitation except for IPSL-CM5A-LR which is likely to be negative trends. It is concluded that four GCMs have likely to be increasing trends in annual mean precipitation while IPSL-CM5A-LR has likely to be negative trends in all four scenarios. Future precipitation for monsoon and winter seasons is likely to have increasing trends for higher scenarios. The lowest scenario RCP-2.6 of IPSL-CM5A-LR and NoerESM1-M has negative trends for monsoon and winter mean precipitation. Li et al. [62] reported similar results and used six GCMs under three emission scenarios to project the potential spatiotemporal changes over Loess Plateau of China during the $21^{\text {st }}$ century and the projected changes were significant. Premonsoon and postmonsoon precipitation will likely follow the same positive trends for future precipitation except for a few scenarios which account for less than $20 \%$. The arithmetic mean of annual precipitation for the past 51 years (1960-2010) was $1360 \mathrm{~mm}$. Considering this value as a baseline RCP-2.6 predicts a change of $9.2 \%$, RCP- 4.5 predicts a change of $8.04 \%$, and RCP-6.0 will likely observe the highest change of $9.79 \%$ and RCP- 8.5 with the lowest change of $7.1 \%$. Similar results reported that long-term precipitation 


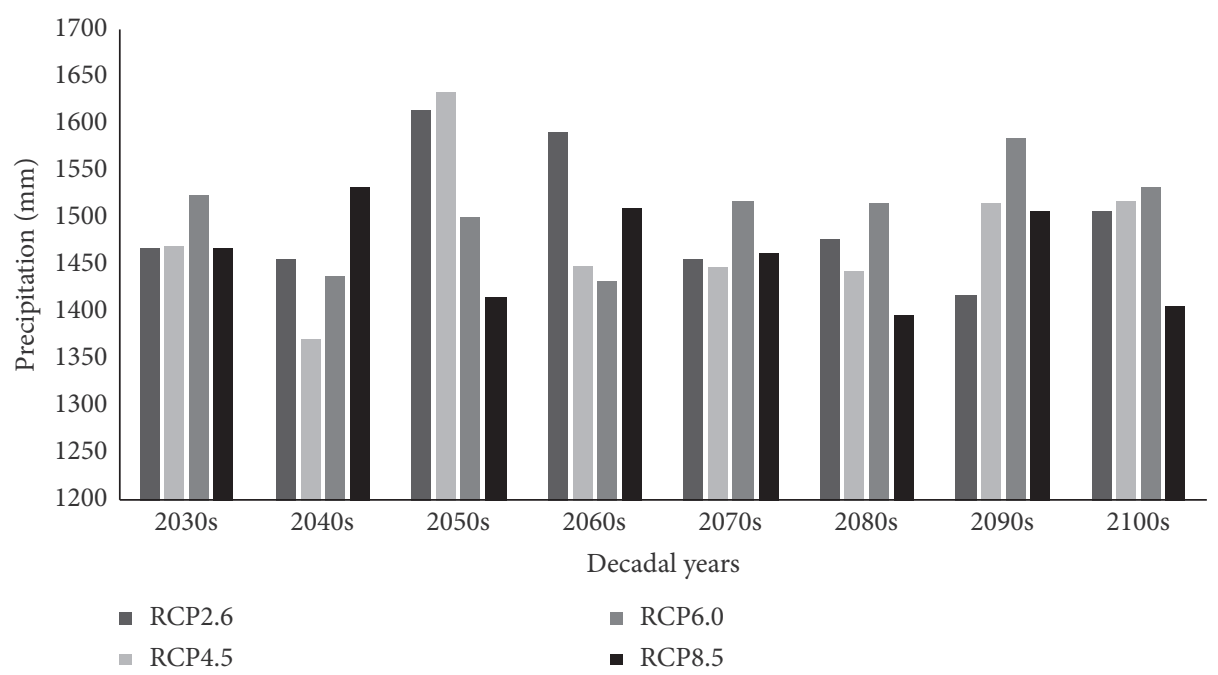

FIGURE 10: Mean decadal segmentation of the annual rainfall from five GCMs under four emission scenarios.

TABLE 7: Decadal mean rainfall (percent change) derived from observed (1960-2010) mean rainfall value 1360 mm and arithmetic mean of five GCMs under four emission scenarios.

\begin{tabular}{|c|c|c|c|c|c|c|c|c|}
\hline Scenario & $2030 s$ & $2040 s$ & $2050 s$ & $2060 s$ & $2070 \mathrm{~s}$ & $2080 s$ & $2090 \mathrm{~s}$ & $2100 \mathrm{~s}$ \\
\hline RCP-2.6 & $1467(7.9)$ & $1457(7.17)$ & 1615 (15.8) & $1591(14.5)$ & $1456(6.6)$ & $1477(7.9)$ & $1418(4.09)$ & 1507 (9.7) \\
\hline RCP-4.5 & $1468.9(8.0)$ & $1371.4(0.84)$ & $1633(16.7)$ & 1449 & $1447(6.05)$ & $1444(5.8)$ & 1516 (10.29) & $1518(10.4)$ \\
\hline RCP-6.0 & $1523.9(12.05)$ & $1437.5(5.7)$ & $1500.7(9.3)$ & $1432(5.0$ & $1518(10.4)$ & $1515(10.2)$ & $1584(14.1)$ & $1532(11.2)$ \\
\hline RCP-8.5 & $1468.45(7.97)$ & $1532(12.7)$ & $1415.5(3.92)$ & $1510.1(9.9)$ & $1461(6.9)$ & $1396(2.5)$ & $1507(9.78)$ & $1405(3.24)$ \\
\hline
\end{tabular}

is projected to increase $6.0 \%$ under rcp 2.6 and $12.0 \%$ under the rcp8.5 scenario over Tibetan Plateau $[32,63]$. This study concludes that $80 \%$ of emission scenarios will likely observe positive trends for annual and seasonal future precipitation. Uncertainties exist in GCMs data and future projections of hydrological parameters which is less than $20 \%$ observed by this study.

\section{Conclusion}

In this study, we evaluate the long-term observed precipitation trend and five GCMs dataset used in the CMIP5 over the Xijiang River Basin at 32 weather stations. There was consistency in the results acquired from the Mann-Kendall, Sen's slope estimator test, and the trend line for all stations during the specified study period. The trend line shows the increasing and decreasing rainfall for stations. The trend in precipitation observed for each station could imply that the changes are more pronounced for certain locations and less for others. Annual precipitation for the past half century observed a decreasing trend. Similarly, winter and monsoon have increasing trends while premonsoon and postmonsoon have downwards trends. The historical precipitation over the Xijiang River Basin showed similar characteristics compared with those of observed historical precipitation with an annual mean precipitation of $1500 \mathrm{~mm}$. Skewness is positive while the dataset is light-tailed distribution. Annual mean precipitation output for future scenarios has likely to be inclined trends except for IPSL-CM5A-LR which showed a negative trend. Decadal segmentation of arithmetic mean of future scenarios concluded that projected precipitation will increase by $8.6 \%$. The reason for these variations needs further study to link the observed trends with climate variability. Thus, the change in trends of rainfall becomes a shred of evidence across the study region to reach a conclusion. These results will possibly enhance the risk for both agriculture and flooding, in both urban and rural areas. Therefore, appropriate flood-control actions should be taken to enhance human mitigation to flood hazards under the changing climate across the Xijiang River Basin.

\section{Data Availability}

Daily precipitation data of 32 weather stations in the Xijiang River Basin for the period of 1960-2010 were provided by National Meteorological Information Centre (NMIC) of the China Meteorological Administration (CMA).

\section{Conflicts of Interest}

The authors declare that they have no conflicts of interest.

\section{Acknowledgments}

This study was supported by the National Key Research and Development Program of China (2017YFC0405900), National Natural Science Foundation of China (51669003), and Guangxi Key R\&D Program (AB16380284). 


\section{References}

[1] R. Pachauri, L. Meyer, G. Plattner, and T. Stocker, IPCC, 2014: Climate Change 2014, Synthesis Report, Geneva, Switzerland, 2014.

[2] S. Wang and Z. J. C. R. Zhang, "Effects of climate change on water resources in China," Climate Research, vol. 47, no. 1-2, pp. 77-82, 2011.

[3] X. Song, S. Song, W. Sun et al., "Recent changes in extreme precipitation and drought over the Songhua River Basin, China, during 1960-2013," Atmospheric Research, vol. 157, pp. 137-152, 2015.

[4] H. Ruimin, Z. Jianyun, B. Zhenxin, Y. Xiaolin, W. Guoqing, and L. Cuishan, "Response of runoff to climate change in the Haihe River basin," Advances in Water Resources, vol. 26, no. 1, pp. 1-9, 2015.

[5] N. Al Aamery, J. F. Fox, and M. Snyder, "Evaluation of climate modeling factors impacting the variance of streamflow," Journal of Hydrology, vol. 542, pp. 125-142, 2016.

[6] Y. Chen, K. Takeuchi, C. Xu, Y. Chen, and Z. Xu, "Regional climate change and its effects on river runoff in the Tarim Basin, China," Hydrological Processes, vol. 20, no. 10, pp. 2207-2216, 2006.

[7] R. Watkins and M. Kolokotroni, "The London Urban Heat Island-upwind vegetation effects on local temperatures," 2012.

[8] C. Xu, J. Zhao, H. Deng et al., "Scenario-based runoff prediction for the kaidu river Basin of the tianshan mountains, northwest China," Environmental Earth Sciences, vol. 75, no. 15, 2016.

[9] Z.-W. Yan, J. Wang, J.-J. Xia, and J.-M. Feng, "Review of recent studies of the climatic effects of urbanization in China," Advances in Climate Change Research, vol. 7, no. 3, pp. 154-168, 2016.

[10] B. S. Bureau, "Beijing 2000 census data," 2002.

[11] C. C. Fan, "Interprovincial migration, population redistribution, and regional development in China: 1990 and 2000 census comparisons," The Professional Geographer, vol. 57, no. 2, pp. 295-311, 2005.

[12] W. Lin, L. Zhang, D. Du et al., "Quantification of land use/ land cover changes in Pearl River Delta and its impact on regional climate in summer using numerical modeling," Regional Environmental Change, vol. 9, no. 2, pp. 75-82, 2009.

[13] K. C. Seto, C. E. Woodcock, C. Song, X. Huang, J. Lu, and R. K. Kaufmann, "Monitoring land-use change in the pearl river delta using landsat TM," International Journal of Remote Sensing, vol. 23, no. 10, pp. 1985-2004, 2002.

[14] S. Chen, W.-B. Li, Y.-D. Du, C.-Y. Mao, and L. Zhang, "Urbanization effect on precipitation over the Pearl River Delta based on CMORPH data," Advances in Climate Change Research, vol. 6, no. 1, pp. 16-22, 2015.

[15] R. A. Pielke, "Land use and climate change," Science, vol. 310, no. 5754, pp. 1625-1626, 2005.

[16] G. Ren, Y. Zhou, Z. Chu et al., "Urbanization effects on observed surface air temperature trends in North China," Journal of Climate, vol. 21, no. 6, pp. 1333-1348, 2008.

[17] PRC, "China's Policies and Actions for Addressing Climate Change," 2008.

[18] K. Trenberth, P. Jones, P. Ambenje et al., "Observations: surface and atmospheric climate change," 2007.

[19] J. T. Houghton, IPCC (Intergovernmental Panel on Climate Change), 1986.

[20] J. J. McCarthy, O. F. Canziani, N. A. Leary, D. J. Dokken, and K. S. White, "Climate change 2001," 2001.
[21] Q. Zhang, C.-Y. Xu, and Z. Zhang, "Observed changes of drought/wetness episodes in the Pearl River basin, China, using the standardized precipitation index and aridity index," Theoretical and Applied Climatology, vol. 98, no. 1-2, pp. 89-99, 2009.

[22] Q. Zhang, C.-Y. Xu, S. Becker, Z. X. Zhang, Y. D. Chen, and M. Coulibaly, "Trends and abrupt changes of precipitation maxima in the Pearl River basin, China," Atmospheric Science Letters, vol. 10, no. 2, pp. 132-144, 2009.

[23] L.-1. Liu, T. Jiang, and F. Yuan, "Observed (1961-2007) and projected (2011-2060) climate change in the pearl river basin," Advances in Climate Change Research, vol. 5, no. 4, pp. 209-214, 2009.

[24] T. Fischer, M. Gemmer, L. Lüliu, and S. Buda, "Temperature and precipitation trends and dryness/wetness pattern in the Zhujiang River Basin, South China, 1961-2007," Quaternary International, vol. 244, no. 2, pp. 138-148, 2011.

[25] Y. Zhang, Y. Luo, and L. Sun, "Quantifying future changes in glacier melt and river runoff in the headwaters of the Urumqi River, China," Environmental Earth Sciences, vol. 75, no. 9, 2016.

[26] Q. Zhang, V. P. Singh, J. Peng, Y. D. Chen, and J. Li, "Spatialtemporal changes of precipitation structure across the Pearl River basin, China," Journal of Hydrology, vol. 440-441, pp. 113-122, 2012.

[27] M. Gemmer, T. Fischer, T. Jiang, B. Su, and L. L. Liu, "Trends in precipitation extremes in the zhujiang river basin, South China," Journal of Climate, vol. 24, no. 3, pp. 750-761, 2011.

[28] L.-T. Zhou and W. Renguang, "Respective impacts of the East Asian winter monsoon and ENSO on winter rainfall in China," Journal of Geophysical Research, vol. 115, no. D2, 2010.

[29] X. Gao, Y. Shi, R. Song et al., "Reduction of future monsoon precipitation over China: comparison between a high resolution RCM simulation and the driving GCM," Meteorology and Atmospheric Physics, vol. 100, no. 1-4, pp. 73-86, 2008.

[30] L. Chen and O. W. Frauenfeld, "A comprehensive evaluation of precipitation simulations over China based on CMIP5 multimodel ensemble projections," Journal of Geophysical Research: Atmospheres, vol. 119, no. 10, pp. 5767-5786, 2014.

[31] L. Feng, T. Zhou, B. Wu, T. Li, and J.-J. Luo, "Projection of future precipitation change over China with a high-resolution global atmospheric model," Advances in Atmospheric Sciences, vol. 28, no. 2, pp. 464-476, 2011.

[32] X. Chong-Hai and X. Ying, "The projection of temperature and precipitation over China under RCP scenarios using a CMIP5 multi-model ensemble," Atmospheric and Oceanic Science Letters, vol. 5, no. 6, pp. 527-533, 2012.

[33] X. Wang, T. Yang, X. Li, P. Shi, and X. Zhou, "Spatio-temporal changes of precipitation and temperature over the Pearl River basin based on CMIP5 multi-model ensemble," Stochastic Environmental Research and Risk Assessment, vol. 31, no. 5, pp. 1077-1089, 2017.

[34] H. Guo, Q. Hu, and T. J. J. O. H. Jiang, "Annual and seasonal streamflow responses to climate and land-cover changes in the Poyang Lake basin, China," Journal of Hydrology, vol. 355, no. 1-4, pp. 106-122, 2008.

[35] H. Hui, L. Hong, and O. Yi, "Flood characteristics of the Xijiang River Basin in 1959-2008," Advances in Climate Change Research, vol. 3, 2009.

[36] Y. Zhu, C. Guo, and X. Huang, "Trend analysis of precipitation extreme values of Xijiang River Basin," China Hydrology, vol. 32, no. 2, pp. 72-77, 2012. 
[37] W. U. C. Alliance, "Options for improving climate modeling to assist water utility planning for climate change," 2009.

[38] T. Fischer, M. Gemmer, B. Su, T. Scholten, and E. S. Sciences, "Hydrological long-term dry and wet periods in the Xijiang River Basin, South China," Hydrology and Earth System Sciences, vol. 17, no. 1, pp. 135-148, 2013.

[39] H. B. Mann, "Nonparametric tests against trend," Econometrica, vol. 13, no. 3, pp. 245-259, 1945.

[40] M. G. Kendall, "Rank correlation methods," 1948.

[41] K. N. Krishnakumar, G. S. L. H. V. Prasada Rao, and C. S. Gopakumar, "Rainfall trends in twentieth century over Kerala, India," Atmospheric Environment, vol. 43, no. 11, pp. 1940-1944, 2009.

[42] A. Rana, C. B. Uvo, L. Bengtsson, and P. P. Sarthi, "Trend analysis for rainfall in Delhi and Mumbai, India," Climate Dynamics, vol. 38, no. 1-2, pp. 45-56, 2012.

[43] S. A. Salman, S. Shahid, T. Ismail, N. bin Abd Rahman, X. J. Wang, and E. S. Chung, "Unidirectional trends in daily rainfall extremes of Iraq," Theoretical and Applied Climatology, vol. 134, no. 3-4, pp. 1165-1177, 2018.

[44] S. Hempel, K. Frieler, L. Warszawski, J. Schewe, and F. Piontek, "A trend-preserving bias correction \& ndash; the ISI-MIP approach," Earth System Dynamics, vol. 4, no. 2, pp. 219-236, 2013.

[45] K. C. Abbaspour, M. Faramarzi, S. S. Ghasemi, and H. Yang, "Assessing the impact of climate change on water resources in Iran," Water Resources Research, vol. 45, no. 10, 2009.

[46] S. A. Vaghefi and K. Abbaspour, "Climate change toolkit (CCT) user guide," 2019.

[47] S. A. Vaghefi, M. Keykhai, F. Jahanbakhshi et al., "The future of extreme climate in Iran (2045-2322)," 2019.

[48] M. Kendall, Rank correlation methods, Charles Griffin, San Francisco, CA, USA, 4th edition, 1975.

[49] P. K. Sen, "Estimates of the regression coefficient based on kendall's tau," Journal of the American Statistical Association, vol. 63, no. 324, pp. 1379-1389, 1968.

[50] F. Hussain, G. Nabi, and M. W. Boota, "Rainfall trend analysis by using the Mann-Kendall test \& Sen's slope estimates: a case study of district Chakwal rain gauge, barani area, northern Punjab province, Pakistan," Science International, vol. 27, no. 4, 2015.

[51] I. Ahmad, D. Tang, T. Wang, M. Wang, and B. J. A. I. M. Wagan, "Precipitation trends over time using Mann-Kendall and spearman's rho tests in swat river basin, Pakistan," Advances in Meteorology, vol. 10, 2015.

[52] A. Mondal, S. Kundu, and A. Mukhopadhyay, "Rainfall trend analysis by Mann-Kendall test: a case study of north-eastern part of Cuttack district, Orissa," International Journal of Geology, Earth and Environmental Sciences, vol. 2, no. 1, pp. 70-78, 2012.

[53] S. Yue, P. Pilon, and G. Cavadias, "Power of the Man$\mathrm{n}$-Kendall and Spearman's rho tests for detecting monotonic trends in hydrological series," Journal of Hydrology, vol. 259, no. 1-4, pp. 254-271, 2002.

[54] T. Salmi, A. Maatta, P. Anttila, T. Ruoho-Airola, and T. Amnell, "Mann-Kendall test and Sen's slope estimates for the trend of annual data," 2002.

[55] S. Chen, Y. Guo, Y. Zheng, and Y. X. Zheng, "Temporal and spatial variation of annual mean air temperature in arid and semiarid region in northwest China over a recent 46 year period," Journal of Arid Land, vol. 2, no. 2, pp. 87-97, 2010.

[56] S. Dai, H. Li, H. Luo, Y. Zhao, and K. Zhang, "Changes of annual accumulated temperature over Southern China during
1960-2011," Journal of Geographical Sciences, vol. 25, no. 10, pp. 1155-1172, 2015.

[57] W. J. Li, H. C. Ren, J. Q. Zuo, and H. L. Ren, "Early summer southern China rainfall variability and its oceanic drivers," Climate Dynamics, vol. 50, no. 11-12, pp. 4691-4705, 2018.

[58] W. Viessman and K. E. Schilling, Social and Environmental Objectives in Water Resources Planning and Management, 1986.

[59] H. Thiel, "A rank-invariant method of linear and polynomial regression analysis, part 3," 1950.

[60] B. Hewitson and R. Crane, "Climate downscaling: techniques and application," Climate Research, vol. 7, no. 2, pp. 85-95, 1996.

[61] Z. Wang, X. Chen, L. Zhang, and Y. J. J. C. H. Li, "Spatiotemporal change characteristics of precipitation in the Pearl River basin in recent 40 years," Meteorology and Atmospheric Physics, vol. 26, no. 6, pp. 71-75, 2006.

[62] Z. Li, F.-L. Zheng, W.-Z. Liu, and D.-J. Jiang, "Spatially downscaling GCMs outputs to project changes in extreme precipitation and temperature events on the Loess Plateau of China during the 21st Century," Global and Planetary Change, vol. 82-83, pp. 65-73, 2012.

[63] F. Su, X. Duan, D. Chen, Z. Hao, and L. Cuo, "Evaluation of the global climate models in the CMIP5 over the Tibetan plateau," Journal of Climate, vol. 26, no. 10, pp. 3187-3208, 2013. 